IZA DP No. 6004

A General Model of Technical Change with an Application to the OECD Countries

Almas Heshmati

Subal C. Kumbhakar

October 2011 


\title{
A General Model of Technical Change with an Application to the OECD Countries
}

\author{
Almas Heshmati \\ Korea University \\ and IZA \\ Subal C. Kumbhakar \\ Binghamton University (SUNY)
}

Discussion Paper No. 6004

October 2011

\author{
IZA \\ P.O. Box 7240 \\ 53072 Bonn \\ Germany \\ Phone: +49-228-3894-0 \\ Fax: +49-228-3894-180 \\ E-mail: iza@iza.org
}

\begin{abstract}
Any opinions expressed here are those of the author(s) and not those of IZA. Research published in this series may include views on policy, but the institute itself takes no institutional policy positions.

The Institute for the Study of Labor (IZA) in Bonn is a local and virtual international research center and a place of communication between science, politics and business. IZA is an independent nonprofit organization supported by Deutsche Post Foundation. The center is associated with the University of Bonn and offers a stimulating research environment through its international network, workshops and conferences, data service, project support, research visits and doctoral program. IZA engages in (i) original and internationally competitive research in all fields of labor economics, (ii) development of policy concepts, and (iii) dissemination of research results and concepts to the interested public.
\end{abstract}

IZA Discussion Papers often represent preliminary work and are circulated to encourage discussion. Citation of such a paper should account for its provisional character. A revised version may be available directly from the author. 
IZA Discussion Paper No. 6004

October 2011

\section{ABSTRACT}

\section{A General Model of Technical Change with an Application to the OECD Countries}

In the neoclassical production functions model technical change (TC) is assumed to be exogenous and it is specified as a function of time. However, some exogenous external factors other than time can also affect the rate of TC. In this paper we model TC via a combination of time trend (purely non-economic) and other observable exogenous factors, which we call technology shifters (economic factors). We use several composite technology indices based on appropriate combinations of the external economic factors which are indicators of different aspects of technology. These technology indices are embedded into the production function in such a way that they can complement to different inputs. By estimating the generalized production function, we get estimates of TC which is decomposed TC into a pure time component as well as several producer specific external economic factors. Furthermore, the technology shifters allow for non-neutral and biased shifts in TC. We also consider a simple model in which the technology shifters are aggregated into one single index. The empirical model uses panel data on OECD, accession and enhanced engagement countries observed during 1980-2006.

JEL Classification: C C33, C43, D24, O33, O47, O57

Keywords: technical change, total factor productivity growth, technology indicator, technology shifter, OECD countries

Corresponding author:

Almas Heshmati

Department of Food and Resource Economics

College of Life Sciences and Biotechnology

East Building, Room 217, Korea University

Anam-dong Seongbuk-gu

Seoul, 136-701

Korea

E-mail: heshmati@korea.ac.kr 


\section{Introduction}

Measurement of total factor productivity (TFP) growth has been increasingly the subject of investigations in many empirical studies on industrial, regional and national productivity (for example, Jorgenson, 1995). These studies have followed several distinct directions. Diewert (1981) classified the various approaches used into: parametric estimation of production and cost functions, non-parametric indices, exact index numbers, and nonparametric methods using linear programming. In the non-parametric approach, the Divisia index has been widely used as a measure of TFP growth over time and considered as a benchmark in growth comparisons. In the parametric econometric model, TFP is further decomposed into several components, of technical change (TC) is often analyzed the most.

In the parametric specification of technology using production or cost functions, a quadratic function of time trend has often been used to represent TC. Baltagi and Griffin (1988) has shown that if a panel data set is available, we could estimate a time specific parameter (general index of TC) referring to the state of technology instead of using time trend. The method has shown evidence of erratic patterns of TC which limits its usefulness (see Kumbhakar and Heshmati, 1996; and Kumbhakar, Nakamura and Heshmati, 2000). In a number of recent studies different generalizations of time trend and general index models of TC have been proposed and their performance and sensitivity using different datasets evaluated (see Heshmati and Nafar, 1998; Kumbhakar, Heshmati and Hjalmarsson, 1999; Kumbhakar, 2000; and Oh, Heshmati and Loof, 2011).

Despite improved data availability and computation power, the econometric approach where TC is represented by a time trend or vector of time dummies still dominates the empirical research. Time trend model is found to be good in revealing long-run trends in TC while general index model is good in capturing year to year variations resulting from various positive and negative shocks that are common to all cross-sectional units. The general index overcomes the trend limitation by not imposing any systematic structure on the behavior of TC. Despite this advantage, it is not much better than time trend in explaining the process of TC. In both approaches TC is modeled entirely in terms of time and they fail to account for the observable determinants of TC and productivity growth. The general index model has offered identification and estimation of the effects of determinants of TC indirectly in a second stage regression (Baltagi, Griffin and Rich, 1995). However, due to the two step procedure it fails to take into account the direct and/or interactive effects of the determinant factors with the traditional inputs.

There is a voluminous literature linking economics and geography with emphasis on economic growth and TC, technology gap, policy and decentralization. For example, Rigby and Essletsbichler (2006) discuss technological variety, technological change and persistence of heterogeneity in techniques of production within economy. Kemeny (2011) examines changing international technology gaps over the recent period of globalization. Analysis of technology level based on average productivity and relative quality reveals a growing disparity between economies and lack of intra-distributional mobility. In a recent study, Martin and Sunley (2011) discuss ways that the new economic geography can be used for policy analysis. The usefulness of the models for policy analysis is found to be constrained by plausibility and credibility of those models. Finally, Rodriques-Pose and 
Ezcurra (2011) examine the relationship between decentralization and economic growth in the OECD countries controlling for fiscal, political and administrative decentralization.

This paper attempts to remedy some of the limitations in the specification and estimation of TC by utilizing observable determinants of TC. Here we argue that, given the inputs (X), TC is likely to be governed by some exogenous variables $(Z)$ which are producer-specific. In addition to $Z$, the time trend or vector of time dummies might be added to reveal the long-run trends or year to year variations in TC. Following Heshmati and Kumbhakar (2011), we generalize the concept of TC and define an aggregator technology index function, $\mathrm{T}(\mathrm{Z}, \mathrm{t})$, which defines the state of the technology and it can vary across crosssectional units as well as over time. This index can be viewed as a hedonic aggregator function which combines multiple attributes of technology into a single index. We use this index as an argument in the production function $\mathrm{Y}=\mathrm{f}(\mathrm{X}, \mathrm{T}(\mathrm{Z}, \mathrm{t}))$. It is not necessary to use a single index technology function. Instead of using one single technology index several technology indices can be specified and used in the production function. One can view these as different components of the aggregate technology index. The time variable can be one index of its own, denoted as $\mathrm{T}(\mathrm{t})$. The previous formulation with a single technology index is a special case of this generalized technology formulation.

Since the rate of $\mathrm{TC}$ is derived by treating $\mathrm{T}(Z, t)$ as a covariate in the production function, it allows us to separate out the impacts of exogenous $Z$ variables and time by breaking down TC into time-specific and Z-specific components. Unlike in the case of time trend and general index models, if $\mathrm{Z}$ variables are observation-specific, TC will vary across cross-sectional units even if the inputs $(\mathrm{X})$ are exactly the same. If no $\mathrm{Z}$ variable (other than time) appears in the model then our estimated measure of TC will be identical to the rate in the time trend and general index models. The rate of TC can further be decomposed into pure and non-neutral components.

For the empirical analysis we use input and output data and production and technology characteristics for 40 mainly OECD countries observed for the period 1980 to 2006. In modeling TC our focus is on various key external economic factors contributing to shift in production across countries and over time. These Z-factors are related to finances, information technology, infrastructure and several other indicators of technology. These shift variables in addition to yielding country-specific rate of TC and factor bias in the overall TC measures, help us to estimate the contribution of the $\mathrm{Z}$ and time variables separately into TC and TFP growth. By using a flexible functional form and panel data methodology and controlling for fixed country effects as well as conducting sensitivity analysis we examine robustness of the estimates of TFP growth and its components for major economies.

The main advantage of the multiple index technology formulation is that it is more flexible in separating the effects of different interrelated producer-specific production technology shifters and as such an important instrument in design and implementation of industrial technology policy in countries with different economic structures. Thus, the analysis is expected to improve our understanding of the causes, patterns and variations in the level and development of growth rate among OECD countries. Information on differences in productivity growth can be important for the governments to formulate better policies of 
allocation and redistribution of productive resources to attain sustainable growth rate and to reduce the growing international and between regional inequalities.

To summarize: the present paper contributes to the literature in a number of ways. First, it explains TC based on observable exogenous external indicators $(Z)$ of technology. These $Z$ variables are not separable from the traditional input variables in the production process. Second, these technology shifters, based on their nature, are further aggregated into several distinct technology shifter groups. Third, we use panel data methodology and flexible functional form in which we control for country-specific effects that are not necessarily associated with technological change. Fourth, the TFP growth rate is decomposed into time driven, technology shifter driven and scale components. Fifth, unlike many other previous growth studies, which mainly apply the growth accounting approach assuming constant returns to scale and fixed shares over long period of time, this paper applies the panel data approach for estimation of the production function and as such does not impose such strong assumptions. Finally, we identify a number of key policy relevant technology shifters and their effects on TFP growth of mainly OECD countries from which we draw policy implications.

The rest of the paper is organized as follows. Section 2 reviews the previous literature on OECD growth studies. Description and analysis of the data is given in Section 3. The factors explaining TC and technological biases are described in Section 4. Specification tests and estimation issues are discussed in Section 5. Empirical results and their implications are discussed in Section 6. The concluding section summarizes the results of this study.

\section{OECD Growth Studies}

We mentioned above that measurement of TFP growth has been increasingly the subject of investigations in many empirical studies on industrial, regional, national and international productivity growth and comparisons. These studies have followed several distinct paths although the parametric and non-parametric methods dominate. The growth accounting is an empirical method that has been used frequently to measure growth in GDP and to break it down into components associated with changes in factor inputs and in production technology. However, the TFP growth is measured as a residual (Solow residual) after accounting for observable inputs. It is possible to relate these residuals in a second step to determinants such as government policies, market, labor, technology, firm, and household characteristics as well as initial conditions. The method is useful if the determinants of factor growth rates and technological change are independent and the factor prices coincide with social marginal products (Barro and Sala-i-Martin, 2004, p. 444). In this paper we attempt to overcome the problem of measuring technological progress by modeling technological change using observable technology shifters instead of computing the rate of $\mathrm{TC}$ residually.

Consistent with our objective here we review the parametric primal approach. First, we review the growth and productivity measurement and its application to international growth studies, followed by applications to OECD studies. It covers theoretical, 
methodological and empirical aspects of measurement of TFP growth and its relationships with determinants of growth. Rapid economic development, technology advancement and high economic growth of the OECD countries since the establishment of the organization and cooperation have been a source of policy debate among transition, emerging and developing countries. A deeper understanding of the OECD growth patterns can be helpful in designing development polices and achievement of potential outcomes.

Many studies analyzing productivity growth for OECD countries exist but none of them covers fully the sample of the members, accession candidate and enhanced engagement countries. ${ }^{1}$ These studies in general investigate diverse aspects covering theory, measurement, methodology and growth empirics. Van Ark et al. (2008) in discussing trends and causes of productivity gap between Europe and US find that the benefits of the New Economy differ between advanced countries. The slowdown in European productivity is in their view attributable to the slower emergence of the knowledge economy in Europe. Madsen (2007) analyze international transmission of knowledge and technology spillover through trade and its effects on TFP over 135 years for the OECD countries.

Trade is found to be important to import of knowledge which is an important contributor to TFP convergence among the OECD countries. Mendi (2007) finds evidence of positive effect of trade in disembodied technology on productivity in OECD countries but not the G7 country group. A separation of embodied spillovers of R\&D measured by trade and corresponding disembodied measured by technological distance in OECD manufacturing industries is presented in Kim and Lee (2004). They investigate the relationship between productivity change and $R \& D$. The result indicates that both domestic $R \& D$ and disembodied spillovers of R\&D have positive effect on TFP growth. Cordoba and Ripoll (2008) show that most of the cross-country differences in output per worker are explained by the barriers to the accumulation of rival factors of human and physical capital rather than accumulation of knowledge capital. Madsen (2010) in analyzing the anatomy of growth finds major contribution from TFP growth driven by R\&D and knowledge spillover and finds evidence of permanent growth effects of R\&D and human capital. Aghion et al. (2009) reflect on the relevance of systems-theoretic approaches to the interdependent policy issues relating to the dynamics of science, technology and innovation and their positive relationship to economic growth.

The literature on measurements and analysis of sources of TFP growth is diverse. These include both non-parametric and parametric approaches. However, the existing literature on technology sources at the cross-country level is inadequate and it does not provide sufficient understanding of the sources of technology changes and modeling it in a single step explaining both production technology and determinants of technological change. In this study, in addition to the methodological contribution concerning the modeling exogenous determinants of technological change, we contribute to the existing research

\footnotetext{
${ }^{1}$ For few studies on growth in OECD see, for example: Bernard and Jones (1996), Gouyette and Perelman (1997), Wong (2006), McMorrow et al. (2010), Maudos et al. (1999), Inklaar and Timmer (2007 and 2009), O'Mahony and Timmer (2009), Hill and Hill (2009), among others.-
} 
which focuses on the investigation of sources of economic growth in OECD. In particular, in addition to traditional inputs, we incorporate several indicators of technology. One key indicator is ICT investment as an infrastructure for economic development in the age of the New Economy. Other indicators are financing technology, trade, inflows of FDI, power generation, MNC and listed companies which play important role in acquisition and absorption of new technology, skills and management. Our data allow us to consider estimation of country-specific productivity growth. Thus, we are able to have a more thorough understanding of the cross-country diversity of growth patterns and its development in OECD.

\section{The OECD Data}

In this paper, we use cross-country unbalanced panel data on the OECD countries during the period 1980-2006. Data are obtained from the World Development Indicator database 2008. The sample consists of 31 OECD member countries, 4 accession candidate countries and 5 enhanced engagement countries. It contains advanced industrialized, newly industrialized, transition and emerging economies. ${ }^{2}$ The data provide information on the contributing factors to the development of the TC and TFP growth in the OECD countries during the recent three decades of both rapid and stagnating economic growth.

The unbalanced data used for estimation of the translog production function and technology indices comprises the following output, inputs and exogenous technology indicator variables for the sample countries. Output is measured as aggregate gross domestic product (GDP) expressed in constant 2000 US\$ in million. The input variables include energy (ENE), capital (CAP) and labor (LAB). Energy use is measured in $\mathrm{kg}$ of oil equivalent per capita. Capital is measured as gross capital formation in constant 2000 US\$ in million. Labor is measured as total labor force in million. GDP and capital are the only variables measured in nominal units. These are converted to fixed 2000 US\$ values.

The technology index is modeled using a number of technology shifters. These include credit guarantee (CRG), trade (TRD), foreign direct investment (FDI), electricity production (ELE), listed domestic companies LDC), government consumption (GOV), computers (PCS), internet use (INT), telecom investment (TEL) and a time trend (T). Credit is defined as domestic credit provided by banking sector measured as percentage of GDP. Trade or openness is defined as sum of imports and exports measured as percentage GDP. FDI is defined as net inflow of foreign direct investment measured as percentage of GDP. Electricity production is measured in million $\mathrm{kWh}$. The listed domestic companies are defined as their total number listed at the stock exchange. The general government final consumption expenditure is measured in percentage of GDP. Computer, telecommunication and other services is defined as percentage of commercial services

\footnotetext{
${ }^{2}$ The OECD member countries are: Australia, Austria, Belgium, Canada, Czech Republic, Denmark, Finland, France, Germany, Greece, Hungary, Island, Ireland, Italy, Japan, Korea, Luxemburg, Mexico, Netherlands, New Zealand, Norway, Poland, Portugal, Slovak Republic, Spain, Sweden, Switzerland, Turkey, Great Britain and Unites State of America. The accession candidate countries include: Eastland, Israel, Russia and Slovenia. The enhanced engagement countries are: Brazil, China, India, Indonesia and South Africa.
} 
imported. Internet use is measured in million users. Telecommunication investment is measured as percentage of revenues generated from the industry. It measures the overall investment intensity in the industry.

The total number of observations (country-year) is 1,037. All countries with the exception of Czech Republic (17), Poland (17), Russia (18) Slovak Republic (23), and Slovenia (17) are observed during the entire period of 27 years. These five countries are observed shorter period but continuously. Table 1 shows the summary statistics of the variables used in the paper, including output, inputs, as well as other production and technology indicators.

Insert Table 1 Summary statistics about here.

\section{Measurement and Decomposition of TFP Growth}

In economics productivity is defined quite broadly. As mentioned previously, there are different approaches employed to measure productivity. Here we focus on TFP as an appropriate measure and estimate it both non-parametrically and parametrically. The focus is on the later, while the former serves only as a benchmark.

\subsection{TFP growth}

In a single or aggregated output case TFP growth is defined as $T \dot{F P}=\dot{Y}-\sum_{j} S_{j} \dot{X}_{j}$, where $Y$ is aggregate output, $X_{j}$ is a vector of inputs $(j=1,2, \ldots . ., \mathrm{J}), S_{j}$ is the cost share of input $X_{j}$ in the total cost, $S_{j}=w_{j} X_{j} / \sum_{j} w_{j} X_{j}, w_{j}$ being the price of input $X_{j}$, and a dot over a variable indicates its annual rate of change. On the other hand, if there are multiple outputs the TFP growth is expressed as TंFP $=\sum_{m} R_{m} \dot{Y}-\sum_{j} S_{j} \dot{X}_{j}$, where $R_{m}$ is the output (revenue) $Y_{m}$ share value, $R_{m}=P_{m} Y_{m} / \sum_{m} P_{m} Y_{m}$, and $P_{m}$ is the price of output $Y_{m}(m=1, \ldots . ., \mathrm{M})$.

Using the above definitions, the $T \dot{F P}$ measure can be computed from the observed data without any econometric estimation. The resulting measure is called the Divisia index of TFP growth. It gives us information about output growth that is not explained by the growth of the factor inputs used in production. The index is mere a measure of our ignorance. In addition the index assumes constant return to scale. The index is nonparametric and as such it does not provide any information on the factors affecting productivity growth.

The main advantage of the parametric econometric approach is that we can both estimate and decompose TFP growth and are able to account for environmental factors and other characteristics. The econometric model can be based on either the primal or the dual formulation. The choice of the dual cost function has some advantages over the primal production function in productivity growth analysis. First, unlike a single production function equation, a cost function can handle multiple outputs quite easily and it can be estimated econometrically. Second, a cost function can be estimated without imposing any 
restriction on the returns to scale. Third, in a service industry outputs may be demand determined where the producer's object is to minimize cost for given output and input prices. Finally, in a cost function approach it is not necessary to assume that output markets are competitive in order to consistently estimate the model parameters. ${ }^{3}$

\subsection{Production function}

In this study we employ a primal or production function approach based on which countries' objective is to maximize output for given inputs available to them. The main advantage with production function is that it does not require information on prices and in addition it allows for non-constant returns to scale in production. It has several desirable and statistically testable properties such as: positive marginal product of inputs, nonemptiness of output, symmetry, monotonicity and convexity. In addition, the production function is assumed to be continuous at any point and twice-continuously differentiable. Assuming a flexible translog functional form to represent the production function with the traditional time trend representation of exogenous TC the model can be written as:

$$
\begin{aligned}
\ln Y_{i t}=\beta_{0} & +\sum_{j=1}^{J} \beta_{j} \ln X_{j i t}+\beta_{t} T_{t}+1 / 2\left(\sum_{j=1}^{J} \sum_{k=1}^{K} \beta_{j k} \ln X_{j i t} \ln X_{k i t}+\beta_{t t} T_{t}^{2}\right) \\
& +\sum_{j=1}^{J} \beta_{j t} \ln X_{j i t} T_{t}+\varepsilon_{i t}
\end{aligned}
$$

where $\ln Y_{i t}$ is the logarithm of output measure of total GDP of country $i(i=1,2, \ldots, \mathrm{N})$ in period $t(t=1,2, \ldots, \mathrm{T})$ and $\ln X_{i t}$ is a vector of logarithm of $J(j=1, \ldots, \mathrm{J})$ inputs. The inputs include energy, capital and labor, $\mathrm{T}$ is a time trend representing exogenous TC and $\beta$ 's are unknown parameters to be estimated. The error term, $\varepsilon_{i t}=\mu_{i}+v_{i t}$, is decomposed into time-invariant country-specific effects $\left(\mu_{i}\right)$ and a random error term $\left(v_{i t}\right)$, with mean 0 and constant variance, $\sigma_{v}^{2}$. The $\mu_{i}$ are assumed to be fixed parameters and are captured by $\mathrm{N}-1$ country dummies.

The specification of TC in (1) is represented by a simple time trend and for the reasons discussed above as such restrictive. Econometrically the production function can be extended to incorporate various 'technology shifters' that are functions of exogenous but observable factors and specified as:

\footnotetext{
${ }^{3}$ For more information about this issue see some of the earlier works found in the Cowing and Stevenson (1981) edited volume "Productivity Measurement in Regulated Industries". For some recent studies see, for example, Atkinson and Halvorsen (1984); Baltagi and Griffin (1988); Kumbhakar (1992); and Bhattacharyya et al. (1997).
} 


$$
\begin{aligned}
\ln Y_{i t}=\beta_{0} & +\sum_{j=1}^{J} \beta_{j} \ln X_{j i t}+\beta_{t} T_{t}+\sum_{m=1}^{M} \beta_{m} T_{m}\left(Z_{i t}^{m}\right) \\
& +1 / 2\left(\sum_{j=1}^{J} \sum_{k=1}^{K} \beta_{j k} \ln X_{j i t} \ln X_{k i t}+\beta_{t t} T_{t}^{2}+\sum_{m=1}^{M} \sum_{l=1}^{L} \beta_{m l} T_{m}\left(Z_{i t}^{m}\right) T_{l}\left(Z_{i t}^{l}\right)\right) \\
& +\sum_{j=1}^{J} \beta_{j t} \ln X_{j i t} T_{t}+\sum_{j=1}^{J} \sum_{m=1}^{M} \beta_{j m} \ln X_{j i t} T_{m}\left(Z_{i t}^{m}\right)+\sum_{m=1}^{M} \beta_{t m} T_{t} T_{m}\left(Z_{i t}^{m}\right)+\varepsilon_{i t}
\end{aligned}
$$

where $T_{m}\left(Z_{i t}^{m}\right)$ are technology indices and $Z^{m}$ are external economic factors labeled as technology shifters. That is, given the traditional inputs, output can change depending on the level of the technology variables that can shift the production function. These shift variables can be grouped into various technology index components, $T_{m}\left(Z_{i t}^{m}\right)$, where each component depends on a subset of mutually exclusive shift variables. Grouping of the shifters into indices can be made by their interrelated nature such as finances, environment, education, R\&D, innovation networks and collaborations, etc. The technology index can be specified as:

$$
T_{m}\left(Z_{i t}^{m}\right)=\ln \left(\sum_{p=1}^{P_{m}} \gamma_{p}^{m} Z_{p i t}^{m}\right), \sum_{p=1}^{P_{m}} \gamma_{p}^{m}=1 \forall m
$$

where $Z^{\mathrm{m}}$ are technology shifters, $P_{m}$ is the number of technology shifters in the technology index and $\gamma$ 's are unknown parameters to be estimated. In this paper we use three technology indices, each based on three technology shifters. The first technology index $\left(T_{1}().\right)$ is constructed around trade and financial market and it is based on credit guarantee, trade and foreign direct investment. The second index $\left(T_{2}().\right)$ is constructed around development infrastructure and market size and is based on electricity generation, listed domestic corporations and government final consumption expenditure. The third index $\left(T_{3}().\right)$ is constructed around information and telecommunication infrastructures and is based on computers and other services, internet users and telecommunication investments. ${ }^{4}$ In defining each of the indices we restrict sum of the weights to be unity (identifying restrictions) so that we can interpret the weights as 'importance' of each shifter on the technology component.

\subsection{Elasticities and growth rates}

The production model outlined above is estimated using fixed effect panel data approach with the specification of a translog functional form. The technology is represented in two ways by: (i) a simple time trend (1) and (ii) a combined simple time trend and technology

\footnotetext{
${ }^{4}$ We also tried to account for other determinants such as: fixed phone lines, mobile phone subscriptions, high technology share of manufacturing exports, personal computers per 100 persons and scientific and technical journal articles, but these were excluded because the model become highly non-linear and not converging.
} 
indices (2 and 3). We call the former the single Time Trend (TT) model whereas the latter is called the technology index (TI) model. The two models are nested and the former is a restricted version of the later.

Based on equations (1) and (2), the input elasticities (E) and the rate of TC can be calculated as follows for each of the two production models:

$$
\begin{aligned}
& E_{j i t}^{T T}=\partial \ln Y_{i t} / \partial \ln X_{j i t}=\beta_{j}+\beta_{j j} \ln X_{j i t}+\beta_{j t} T_{t} \\
& E_{j i t}^{T I}=\partial \ln Y_{i t} / \partial \ln X_{j i t}=\left(\beta_{j}+\beta_{j j} \ln X_{j i t}+\beta_{j t} T_{t}\right)+\left(\sum_{j=1}^{J} \beta_{j m} Z_{m i t}\right) \\
& T C_{i t}^{T T}=\partial \ln Y_{i t} / \partial T_{t}=\beta_{t}+\beta_{t t} T_{t}+\sum_{j} \beta_{j t} \ln X_{j i t} ; \text { and } \\
& T C_{i t}^{T I}=\partial \ln Y_{i t} / \partial T_{t}=\left(\beta_{t}+\beta_{t t} T_{t}+\sum_{j=1}^{J} \beta_{j t} \ln X_{j i t}\right)+\left(\sum_{m=1}^{M} \beta_{t m} Z_{m i t}\right)
\end{aligned}
$$

In similar way the overall elasticity for each technology index, here $T_{m}\left(Z_{i t}^{m}\right)$, is also calculated from (2):

$$
E_{\text {mit }}^{Z}=\partial \ln Y_{i t} / \partial \ln T_{m}\left(Z_{i t}^{m}\right)=\left(\beta_{m}+\beta_{m m} \ln Z_{m i t}+\sum_{j=1}^{J} \beta_{j m} \ln X_{j i t}+\beta_{t m} T_{t}+\beta_{Z l} T_{m}\left(Z_{i t}^{m}\right)\right)
$$

Note that exogenous rate of technical change $\left(\mathrm{TC}^{\mathrm{TI}}\right)$ in $(5 \mathrm{~b})$ can further be decomposed into the pure $\left(\beta_{t}+\beta_{t t} T_{t}\right)$, non-neutral $\left(\sum_{j} \beta_{j t} \ln X_{j i t}\right)$, and technology index $\left(\sum_{m} \beta_{t m} T_{m}\left(Z_{i t}^{m}\right)\right)$ components. Pure TC refers to neutral shift of the production function due to time alone, non-neutral TC means input biased $\mathrm{TC}$, and technology index components is a results of effect of known exogenous technology shifters. This last component distinguishes the two formulations of TC in (1) and (2). TC is biased if the marginal rate of substitution between any two inputs measured along a ray through the origin is affected by TC. The bias effect depending on the sign is interpreted as input using (positive) and input saving (negative). It implies that TC will tend to influence the relative contribution of each input to the production process.

Estimation of returns to scale (RTS) is obtained by summing all of the input elasticities calculated in equation (4a) and 4(b):

$$
\begin{aligned}
& R T S_{i t}^{T T}=\sum_{j=1}^{J} E_{j i t}^{T T} ; \text { and } \\
& R T S_{i t}^{T I}=\sum_{j=1}^{J} E_{j i t}^{T I}
\end{aligned}
$$

where $E_{j i t}$ is the elasticity of output for country $i$ with respect to input $j$ at period $t$. It measures the percentage change of output in response to a $1 \%$ increase in all inputs 
simultaneously. Technology is said to be exhibiting increasing, constant or decreasing returns to scale, respectively, if RTS greater than, equal to or less than 1. All input elasticities, returns to scale and TC are computed at every data point allowing analysis of variation in responsiveness's along individual country, country groups and time dimensions. By using equations (4) to (8), the parametric TFP growth for both TT and TI models can be obtained as follow:

$$
\begin{aligned}
& T \dot{F} P_{i t}^{T T}=T C_{i t}^{T T}+\left(R T S_{i t}^{T T}-1\right) \sum_{j=1}^{J} E_{j i t}^{T T} \dot{X}_{j i t}=T C_{i t}^{T T}+S C A L E_{i t}^{T T} ; \text { and } \\
& T \dot{F} P_{i t}^{T I}=T C_{i t}^{T I}+\left(R T S_{i t}^{T I}-1\right) \sum_{j=1}^{J} E_{j i t}^{T I} \dot{X}_{j i t}+\sum_{m=1}^{M} E_{m i t}^{Z} \dot{T}_{m}\left(Z_{i t}^{m}\right)=T C_{i t}^{T I}+S C A L E_{i t}^{T I}+T Z_{i t}
\end{aligned}
$$

where $\mathrm{TZ}$ and $\mathrm{TC}^{\mathrm{TI}}$ together measure the overall rate of $\mathrm{TC}$ in the TI model. The $\mathrm{TC}^{\mathrm{TI}}$ part is due to time alone whereas the $\mathrm{TZ}$ part is due to other external but observable economic factors. In our application $\mathrm{TZ}$ is a weighted average of the three technology index components, where the weights are the marginal effects of the index components. The overall $\mathrm{TZ}$ index is the sum of the product of the technology elasticity and growth rate of technology index, viz.:

$$
T Z_{i t}=\sum_{m=1}^{M}\left(\partial \ln Y_{i t} / \partial \ln T_{m}\left(Z_{i t}^{m}\right)\right)\left(\dot{T}_{m}\left(Z_{i t}^{m}\right)\right)
$$

It should be noted that, under constant returns to scale (CRS) and competitive output markets, TFP growth and TC are identical (Solow, 1957). In such a case it is not necessary to estimate anything econometrically, but computing Divisia index directly from the data, given information on input cost shares and revenue shares is available. However, if the objective of producers is to minimize cost (given outputs) or maximize output (given inputs), and the constant returns to scale and perfectly competitive output (input) market assumptions are relaxed, then it is possible to establish a relationship between the Divisia index and the TFP growth components (Denny et al., 1981). The TFP growth in (8a) and (8b) can be obtained from a parametric cost function or production function as shown above for the latter case. The first component of TFP growth is TC and the second component is the Scale component, which is zero if RTS is unity. The last component is zero if either the marginal effect of every technology shifter is zero or these shift variables are time-invariant.

It is worth to mention that, even with a CRS technology, other non-inputs factors that can explain productivity growth may exist. If these factors are observed, we can separate the contribution of external economic factors that are under the control of the producers and those purely external non-economic factors exogenous to the firm by estimating the underlying production technology econometrically. The external factors which define the production environment, could affect profitability, survival and productivity growth of firms. These factors are usually taken into account in the endogenous growth literature. Morrison (1986) and Morrison and Siegel (1999) include these factors in the productivity growth analysis. They point out that such external factors affect the cost-output 
relationship of the firm and can be explicitly included into the model as non-neutral shift variables. See also Winston (1993) and Vickers (1995). Here we use these non-economic factors as technology shifter and in the context of drivers of technological change.

The non-economic factors can be technology related independent variables in development accounting which are paid large attention to in recent economic literature. In the econometric literature on the determinants of economic growth, we are currently facing around 100 popular explanatory variables. However, the augmented growth models discussed in Barro and Sala-i-Martin (2004) and Aghion and Howitt (2009), incorporate some combinations of determinants of economic growth.

\section{Specification Tests and Estimation Procedures}

We specify and estimate a translog production function for OECD countries observed for the period 1980-2006. Output is measured as gross domestic product. The vector of inputs includes energy, capital and labor. The technology index is modeled using three technology indices each consisting of three technology shifters. The first index (Index1) is based on credit guarantee, trade and foreign direct investment. The second index (Index2) is based on electricity production, listed domestic companies and government consumption. The third index (Index3) is constructed using computers, internet use and telecom investment. The definition of each of these variables is provided above in the model data section. In specifying the technology index we tried a number of other technology indicators, but the model specification was highly nonlinear and difficult to further generalize.

In addition we use dummy variables to control for unobserved time-invariant countryspecific effects such as skills, planning and management differences, and location advantages/disadvantages of the countries. These fixed effects play an important role concerning stability of the effects of inputs and technology shifters (see Ahion and Howit, 2009; Kreuger and Lindahl, 2001; and Vandenbussche, Aghion and Meghir, 2006). A simple time trend is added to the specification of the production function to capture possible trend in the use of inputs and output produced. It captures the unobserved exogenous time driven components of TC and productivity growth as well as country specific effects such as government economic policy effects.

We investigate the issues of multicollinearity and confounded effects (see Table 2). The explanatory variables energy $(0.246)$, capital $(0.966)$ and labor $(0.196)$ are positively and highly correlated with GDP. There is also a positive association between GDP and trend (0.081). The energy is positively correlated with capital $(0.187)$ and trend $(0,108)$ but negatively with labor (-0.298). Capital and labor (0.266) and capital and energy (0.093) are positively correlated. Labor is not correlated with time trend, but capital and energy are. The correlation coefficient among the input variables shows that there is no serious multicollinearity problem. Concerning the technology shifters, credit, electricity production, listed domestic companies, and investment user are positively correlated with GDP, but trade, net FDI inflows, government consumption and telecom investment are negatively correlated with GDP. There are both positive and negative correlations relationships among the technology shifters within and between the index components. 


\section{Insert Table 2 Correlation matrix about here}

Given the model outlined above, several model specification tests are possible. First, functional form can be tested by testing a flexible translog form versus a simple CobbDouglas or intermediate Generalized Cobb-Douglas forms. Second, one can test significance of the three technology components individually or jointly. Third, a test of single or multiple technology index components is possible. The first test, based on F-test, accepts the translog form. The second test shows the presence of three technology index components. We could not perform the third test because the model with a single technology index with six or nine shift variables did not converge. Various measures shown in equation 4 through equation 9 such as predicted indices, marginal effects of indices and individual shift variables, rate of TC, input elasticities, returns to scale, TFP and its decomposition into TC, scale and technology index components, and their respective share are computed at each point of the data using the estimated parameters. Details on these are provided in the next section.

\section{Empirical Results}

\subsection{Estimation issues}

The estimation results for translog technology index model and its restrictive counterparts including a simple Cobb-Douglas (Model 1), a generalized Cobb-Douglas (Model 3) and a translog (Model 4) model specifications with time trend and with technology indicators treated as production environmental variables (Model 2) are reported in Table 3 . In the translog model all the parameters (with the exception of interactions between the inputs and time trend) are highly significant. The results suggest significant heterogeneity among the countries.

\section{Insert Table 3 Parameter estimates about here}

In the case of technology index model (Model 5), the explanatory variables can be grouped into technology index, inputs and time trend and country fixed effects. All the 6 technology related parameters are highly significant. However, only 26 of the 36 parameters associated with the inputs, time trend and composite technology indices are statistically significant at less than $10 \%$ level. Country effects, with the exception of 6 are significant at the less than 10 level of significance. The result shows evidence that the degree of country heterogeneity is high. The parameters of the three technology indices are of expected sign.

\subsection{The simple time trend model}

The input elasticities are estimated from the derivatives of the production functions with respect to energy, capital and labor inputs using formula (4a). With few exceptions (three cases of labor and two cases of energy) all point elasticities across countries are positive. All point input elasticities over time are positive. The sample averages of the input elasticities from the simple time trend model are positive $(0.233,0.236$ and 0.494 , 
respectively). The average returns to scale (7a) is 0.963 suggesting decreasing return to scale. The rate of $\mathrm{TC}(5 \mathrm{a})$ is positive indicating technical progress at the rate of 1.27 percent per annum. This coupled with the small negative scale effect results produced a TFP growth rate (8a) of 1.22 percent per year. Variation in the TFP growth is much higher than that of the rate of TC. In order to conserve space the simple time trend model results are not reported in Table 4.

\subsection{Input elasticities and returns to scale in the technology index model}

The sample averages of the input elasticities (equation $4 \mathrm{~b}$ ) based on the technology index model are also as expected positive, 0.286, 0.230 and 0.473 , and is in agreement with the simple time trend model results. Calculated correlations between the input elasticities show that energy and capital are positively correlated while labor is negatively correlated with both energy and capital. Similar correlation relationship is found with economies of scale. The average returns to scale (7b) is 0.989 . However, it is close to 1 suggesting not being statistically different from constant returns to scale. The scale effect is small and negative $(-0.060$ percent). The dispersion in labor elasticity is largest $(0.378)$ causing large variations in the returns to scale $(0.242)$.

The input elasticities and returns to scale across individual OECD countries, country groups and over time are reported in Table 4. With the exception of four country cases concerning labor and one case of energy all average input elasticities across countries are positive and consistent with our expectations. However, the input elasticities vary greatly among the countries mainly when labor is concerned. The average returns to scale measure in 19 cases is less than 1 and in remaining 21 country cases greater than 1 suggesting decreasing and increasing economies of scale, respectively. In examining the differences across country groups we observe large differences in the input elasticities and returns to scale.

\section{Insert Table 4 Input elasticities and RTS across countries and time about here}

The mean input elasticities and returns to scale are almost constant over time. The energy input elasticity show a negative trend, while capital and labor show minor fluctuations that are attributed to the interaction of inputs and technology indices which have stronger impacts on the latter two inputs and reverse the trend effects. Returns to scale is as a result of time trend specification of non-neutral component is declining over time from 1.045 in 1960 to 0.961 in 2006. The switching point is in 1991.

\section{Insert Figure 1 RTS and input elasticities over time about here}

\subsection{Technology index and technical change}

The rate of TC in the simple time trend production function model is computed using (5a). The first and second order coefficients of time are significant suggesting increasing growth at an increasing rate. The interactions of time with energy, capital and labor suggest input saving TC although they are statistically insignificant. The neutral component is large and 
determining the overall rate of $\mathrm{TC}$. The sample average rate of $\mathrm{TC}$ is $1.27 \%$ and it ranges from $0.78 \%$ to $1.68 \%$ per annum. It is the main contributor to TFP growth which is on the average $1.22 \%$ per annum. ${ }^{5}$

In the technology index model, the rate of TC is computed using the formula (5b). It is determined by several components including time trend, technology indices and their interactions among themselves as well as with the production function inputs. All of the technology shifters have positive and significant effects on output. The mean elasticity of production with respect to the three composite technology indices calculated using the formula (6) is $0.043,-0.162$ and 0.080 .

The mean rate of TC from the technology index model is $1.44 \%$ per annum and standard deviation $0.40 \%$. It varies from $0.10 \%$ to $3.16 \%$. The main source of TC is the neutral time driven component, while the share of the index part is on the average $10.74 \%$. TC in turn is the main contributor to TFP growth which is on the average $1.54 \%$ per year with $2.28 \%$ dispersion around the mean value. The index component is positively correlated with the rate of TC $(0.073)$ and TFP growth rate $(0.813)$, while TC and TFP correlation coefficient is 0.199 . Table 5 reports the correlation matrix of estimated TFP and its Index, TC and Scale components. The insight provided here points to the fact that despite incorporation of technology shifters, the time driven component of TC remains the main contributor and dominates the level and development of the rate of technical and total factor productivity growth. The pattern might be due to poor data availability on important technology shifters.

\section{Insert Table 5 on Correlation matrix of TC and TFP about here}

The elasticities of production with respect to technology index components and their marginal effects for each country and time period is reported in Table 4 . The elasticity of index 2 is much higher in level than the remaining two indices across most countries and over time. The marginal effects vary in sign and level across the countries and indices dimensions. Index 2 shows a higher frequency of negative values. The index 1 and 2 yearly averages are all the time positive and negative, respectively, while index 3 switches from negative to positive in 1993.

\subsection{TFP growth and its decomposition}

The OECD countries differ by the size of their economies and productivity growth rates. In reporting the results we used weighted averages. The weighted average rate of TC, TFP growth and their decomposed components using country, country group and yearly shares of overall GDP, is computed and the weighted mean values for different countries, country groups and years are reported on Table 6.

Insert Table 6 on Mean values of weighted TC, TFP growth about here

The mean value of the GDP-weighted rate of TC (by country) is 1.52 percent. It varies between $1.00 \%$ and $2.33 \%$. The corresponding weighted average by country group (1.61,

\footnotetext{
${ }^{5}$ Details are not reported here to conserve space.
} 
$1.41 \sim 1.81)$ is higher while those by year $(1.35,0.84 \sim 2.20)$ is lower as the country groups and years are assigned different overall weights. The numbers in parentheses are mean, minimum and maximum percentage values. Calculation of the weighted average TFP growth has stronger implications when the growth rate is reported by country (1.70, $0.31 \sim 3.31)$, country group $(1.06,0.47 \sim 1.84)$ and years (1.61, 0.40 5.07). Applications of GDP weights has the strongest implications for the index component of TFP growth where the averages are by country $(0.12,-5.85 \sim 1.64)$, country group $(-0.89,-3.77 \sim 0.62)$ and years $(0.39,-0.48 \sim 2.87)$. Similarly the weighted scale component averages and their dispersion vary in the country $(-0.04,-2.75 \sim 1.19)$, country group $(-0.53,-1.56 \sim 0.02)$ and years $(-0.17$, $-0.66 \sim 0.10)$ dimensions.

\subsection{Country level growth heterogeneity}

The country level mean index of the overall TFP growth is $9.77 \%$ (21.85). The corresponding by country group and years are $14.61 \%(8.70)$ and $15.47 \%(19.67)$. The numbers in parenthesis are the standard deviations. The sub-component index 2 across countries is the main contributor to the overall technology index where its share is highest (48.49\%) compared with index $1(25.76 \%)$ and index 3 (25.75). The corresponding index shares however differ when looking at country groups $(16.73,61.04,22.24)$ and years $(19.33,58.57,22.10)$. The percentage (mean and standard deviation) contributions from the exogenous rate of TC to TFP growth vary across countries $(63.75 \%, 35.74)$, country groups $(48.15 \%, 47.55)$ and years $(75.03 \%, 28.33)$. Similar tendencies are found when looking at the percentage contributions from the scale component to TFP growth across countries $(9.87 \%, 23.87)$, country groups $(21.55 \%, 34.78)$ and years $(-0.78 \%, 19.72)$.

Result show that the countries differ by the size and productivity growth rates. The GDPweighted average rate of TC, TFP growth and their decomposed components by country, county group and over time is reported in Table 6 . The table shows that the GDP weighted rate of TC is highest for Slovenia, Slovakia, India, China and Czech Republic, of which mostly belong to the accession and enhanced engagement countries. The lowest rates of TC are in Switzerland and Mexico. Countries at different levels of development like Brazilian, Canada, Finland, Israel, Korea, Norway and Sweden are representing the sample average rate. Despite the relative high average level of development among the sample countries, we find indication of backwardness where countries with low levels of development grow faster.

\section{Insert Figure 2 TFP growth and its components across countries about here}

There is low correlation (0.199) between TC and TFP growth rates. On the other hand TFP is highly correlated with technology index (0.813) and scale (0.377) components. The countries with the highest TFP growth rates are Slovenia, Luxembourg, India and Czech Republic, while Russia, South Africa and Chile are showing the lowest growth rates. The higher correlation between technology index and TFP growth show evidence of positive 
effects of exogenous technology shifter but not necessarily explaining the level variations perfectly. ${ }^{6}$

\subsection{Growth dynamics}

There is a clear increasing trend in the development of the rate of TC over time. It is a result of the use of a time trend to represent the time driven exogenous technological change and its interactions with the other variables in the production function. The rate of TC is continuously increasing from $0.8 \%$ in 1980 to $2.2 \%$ in 2006 . On the other hand, there is no such trend in the scale and technology index components. The scale effect is negative and small while the technology index is positive and larger. The level of TFP growth is to a large extent determined by the TC component but its year to year variation is determined by the technology index component. The highest TFP growth rates are found in 2006 (5.1\%), 2001 and 2005 (2.8\%) followed by 1990 and 1998 (2.3\%). In several years (1980, 1984, 1993 and 1994 the growth rate is low and in the interval $0.4 \%$ and $0.8 \%$.

Insert Figure 3 TFP growth and its components over time about here

The mean technology index component share to the TFP growth is $15.47 \%$ (19.67). It varies over time between -26.52 and 51.83 . There is no systematic trend in its development over time. The average scale share is much lower $(-0.78 \%)$ with large dispersion $(19.72 \%)$ in the interval -54.16 and 55.33. The largest share of TFP growth is arising from TC component. Its share is on the average $75.03 \%$ and with $28.30 \%$ dispersion. It varies between -7.90 and $121.17 \%$. The negative scale effect is causing the share of TC to exceed the 0-100 interval. There are some periodical trends in the share of TC component, but no such trend is found in the shares of technology index, and scale components contributions to the TFP growth rate.

Insert Figure 3 TFP growth and its components shares over time about here

\subsection{The Chinese and Indian Progress and EU debt crisis}

The GDP weighted mean economic growth of OECD countries during this relatively long study period is $1.70 \%$ and it ranges from -0.31 and $+3.31 \%$ per annum. The main contributor to the TFP growth rate is the exogenous rate of TC with an average of $1.52 \%$. In recent decades China and India have turned into major players in the global economy. However, their average TFP growth rates are low but the rate of TC high. The low average TFP growth rates are due to their decreasing economies of scale. However, during the recent global recession China and India have emerged as two of few major economies registering continuous high growth rates and seen as major forces that can help to bring the world economy out of the current deep recession. The growth rate of GDP in 2009 was $9.2 \%$ for China and $8.0 \%$ for India (ADB, 2011) while it was negative for almost all

\footnotetext{
${ }^{6}$ In order to conserve space we do not report all results discussed are, but these can be obtained from the authors upon request.
} 
industrialized countries (CBC, 2011a and 2011b). In particular the Chinese active reform and state led growth model can be of use to major developing economies. The gradual removal of different interventions has affected the flow of resources to productive areas and growing competition and leading role of state has enabled the growth rate to accelerate.

China and India have been successful in attracting FDI and their investment in fixed assets is increased. Basu (2009) provides a comparison of the two economies. The high investment rate and accumulation of capital stock together with acquisition of technology, management and skill and effects of learning by doing has created a strong production base. Exports have increased much more than import leading to large positive trade balance in particular in China's case from 1995. The state controlled exchange rate has been a source of China's international competitiveness and rapidly expanded its export. It also has been a source of criticism from Western countries concerning the trade balance and the prospect for a possible deterioration of global economic recovery. The gradualist approach and currency and capital account control seemed effectively sheltered China from the 1997 financial crisis and full effect of 2008 global economic crisis.

There are significance differences in the level of growth across individual countries as well as between groups of countries. In recent years and following the global economic crisis a number of countries have faced difficulties concerning their accelerating public debts and banking insolvencies. These countries are subject to forced recovery programs imposed by the European Union and international banks (IMF and World Bank). This group of countries includes Iceland $(1.8,1.1)$, Ireland $(1.6,2.6)$, Spain $(1.4,1.7)$, Portugal $(1.4,1.5)$ and Greece $(1.2,1.8)$. The number in parenthesis is their average GDP-weighted TC and TFP growth rates. They have relatively low growth rates but not exactly a good predictor of their post crisis performance. The pre-crisis low growth rate is possibly the driving force behind their low recovery, laggard development and increasing gap in welfare which will further deteriorate as a result of necessary structural programs aimed to bring their finances under control.

\section{Summary and Conclusions}

In this paper we considered estimation of TC and total factor productivity growth (TFPG) by utilizing both observable internal and external determinants of technological change. Results are based on an unbalanced panel data on output, inputs and technology and production characteristics for 40 OECD member, accession and enhanced agreement countries observed for the period 1980 to 2006. In modeling TC our focus is on key technology shifters associated with it. These technology shifters are domestic credit, FDI, trade share of GDP, listed domestic companies, electricity production, government consumption, computer imports, internet users and telecom investment. We estimated TFPG and decomposed it into TC and scale economies components as well as our proposed technology index component. The marginal effects of individual technology indicators on productivity growth are also estimated along with various input elasticities. All the measures are country-specific and time varying. 
Estimates of TFPG and its components are found to vary greatly and dispersions in the technology index components are found to be large. The sources of TFPG differ across countries and are mainly attributed to differences in the exogenous rate of $\mathrm{TC}$ and technology index components. The scale effect is negligible and on the average it contribution to growth is negative due to the presence of decreasing returns to scale.

The analysis is expected to improve our understanding of the causes and patterns of crosscountry TC and TFPG in OECD countries. It enhances our knowledge on the recent three decades of unbalanced economic growth and development among the industrialized, newly industrialized, transition and emerging economies. Information on differences in TFPG among countries is important for the national, EU and other regional economies to formulate coordinated policies of allocation and redistribution of productive resources. This can help in designing policies to reduce the growing within and between regional inequalities as well as reducing the impacts of global economic crisis on some economies facing difficulties concerning, indebtedness, unemployment and stagnated growth.

\section{References}

Aghion P., P.A. David and D. Foray (2009), "Science, Technology and Innovation for Economic Growth: Linking Policy Research and Practice in STIG System," Research Policy 38, 681-693.

Aghion P. and P. Howitt (2009), "The Economics of Growth," The MIT Press, MA Cambridge: MIT Press.

Asian Development Bank (2011), “Asian Development Outlook 2011: South-South Economic Links", The Asian Development Bank.

Atkinson S.E. and R. Halvorsen (1984), "Parametric efficiency tests, economies of scale, and input demand in U.S. electric power generation", International Economic Review 25(3), 647-662.

Baltagi B.H. and J.M. Griffin. (1988), “A Generalized Error Component Model with Heteroscedastic Disturbances," International Economic Review 29, 745-753.

Baltagi B.H., J.M. Griffin and D.P. Rich (1995), "The measurement of firm-specific indexes of technical change," The Review of Economics and Statistics LXXVII, 654663.

Bernard A.B. and C.J. Jones (1996), "Comparing Apples to Oranges: Productivity Convergence and Measurement across Industries and Countries," American Economic Review 86(5), 1216-1238.

Barro R.J. and X. Sala-i-Martin (2004), "Economic Growth,” Cambridge, MA: MIT Press, Second edition.

Basu S.R. (2009), "Comparing China and India: Is the dividend of economic reforms polarized?," European Journal of Comparative Economics 6(1), 57-99.

Bhattacharyya A., A. Bhattacharyya and S.C. Kumbhakar (1997), "Changes in economic regime and productivity growth: a study of Indian public sector banks", Journal of Comparative Economics 25, 196-219.

Conference Board of Canada (2011a), "World Outlook Summer 211: Global Economic Trends and Perspective", The Conference Board of Canada. 
Conference Board of Canada (2011b), "U.S. Outlook Summer 211: Economic Forecast", The Conference Board of Canada.

Cordoba J.C. and M. Ripoll (2008), "Endogenous TFP and Cross-Country Income Differences," Journal of Monetary Economics 55, 1158-1170.

Cowing T.G. and R.E. Stevenson (1981), Eds. Productivity Measurement in Regulated Industries, Academic Press, New York, NY.

Denny M., M. Fuss and L. Wavennan (1981), "The Measurement and Interpretation of Total Factor Productivity in Regulated Industries, with an Application to Canadian Telecommunications", in: Thomas G. Cowing, Rodney E. Stevenson (Eds.), Productivity Measurement in Regulated Industries, Academic Press, New York, 1981, pp. 179-212.

Diewert W.E. (1981), "The theory of total factor productivity measurement in regulated industries", in: T.G. Cowing, R.E. Stevenson (Eds.), Productivity Measurement in Regulated Industries, Academic Press, New York, 1981.

Gouyette C. and S. Perelman (1997), "Productivity Convergence in OECD Service Industries," Structural Change and Economic Dynamics 8, 279-295.

Heshmati A. and S.C. Kumbhakar (2011), "Technical Change and Total Factor Productivity Growth: The Case of Chinese Provinces," Technological forecasting and Social Change 78, 575-590.

Heshmati A. and N. Nafar (1998), "A Production Analysis of the Manufacturing Industries in Iran," Technological Forecasting and Social Change 59, 183-196.

Hill R.J. and T.P. Hill (2009), "Recent Development in the International Comparison of Prices and Real Output," Macroeconomic Dynamics 13, 194-217.

Inklaar R. and M.P. Timmer (2007), "International Comparisons of Industry Output, Inputs and Productivity Levels: Methodology and New Results,“ Economic System Research 19(3), 343-363.

Inklaar R. and M.P. Timmer (2009), "Productivity Convergence Across Industries and Countries: The Importance of Theory-Based Measureemnt," Macroeconomic Dynamics 13, 218-240.

Jorgenson D. (1995), "Productivity", Volume 1 and 2, MIT Press, Cambridge, Mass, 1995.

Kemeny T. (2011), "Are international technology gaps growing or shrinking in the age of globalization?", Journal of Economic Geography 11, 1-35.

Kim J.W. and H.K. Lee (2004), "Embodied and disembodied international spillovers of R\&D in OECD manufacturing industries", Technovation 4, 359-368.

Kreuger A.B. and M. Lindahl (2001), "Education for Growth: Why and For Whom?," Journal of Economic Literature XXXIX, 1101-1136

Kumbhakar S.C. (1992), "Allocative distortions, technical progress, and input demand in U.S. airlines: 1970-1984”, International Economic Review 33(3), 723-737.

Kumbhakar S.C. (2000), "Estimation and Decomposition of Productivity Change when Production is not Efficient: A Panel Data Approach," Econometric Reviews 19, 425460.

Kumbhakar S.C. and A. Heshmati (1996), "Technical Change and Total Factor Productivity Growth in Swedish Manufacturing Industries", Econometric Reviews 15(3), 275-298. 
Kumbhakar S.C., A. Heshmati and L. Hjalmarsson (1999), "Parametric Approaches to Productivity Measurement: A Comparison among Alternative Models," Scandinavian Journal of Economics 101, 405-424.

Kumbhakar S.C., S. Nakamura and A. Heshmati (2000), "Estimation of Firm-Specific Technological Bias, Technical Change and Total Factor Productivity: A Dual Approach", Econometric Reviews 19(4), 493-515.

Martin R. and P. Sunley (2011), "The new economic geography and policy relevance", Journal of Economic Geography 11, 357-369.

McMorrow K., W. Roger and A. Turrini (2010), "Determinants of TFP Growth: A Close Look at Industries Driving the EU-US TFP Gap," Structural Change and Economic Dynamics 21, 165-180.

Madsen J.B. (2007), “Technology Spillover through Trade and TFP Convergence: 135 Years of Evidence for the OECD Countries," Journal of International Economics 72, 464-480.

Madsen J.B. (2010), "The Anatomy of Growth in the OECD since 1870," Journal of Monetary Economics 57, 753-767.

Maudos J., J.M. Pastor and L. Serrano (1999), “Total Factor Productivity Measurement and Human Capital in OECD Countries," Economic Letters 63, 39-44.

Mendi P. (2007), "Trade in Disembodied Technology and Total Factor Productivity in OECD Countries," Research Policy 36, 121-133.

Morrison C. (1986), "Productivity measurement with non-static expectations and varying capacity utilization: an integrated approach", Journal of Econometrics 33, 51-74.

Morrison C. and D.S. Siegel (1999), "Scale economies and industry agglomeration externalities: a dynamic cost function approach", American Economic Review 89, 272 290.

Oh D.H., A. Heshmati and H. Lööf (2011), "Technical Change and Total Factor Productivity Growth for Swedish Manufacturing and Service Industries", Applied Economics, forthcoming.

O’Mahony M. and M.P. Timmer (2009), "Output, Input and Productivity Measures at the Industry Level: The EU KLEMS Database," The Economic Journal 119, F374-F403.

Rigby D.L. and J. Essletzbichler (2006), "Technological variety, technological change and a geography of production techniques", Journal of Economic Geography 6, 45-70.

Rodriguez-Pose A. and R. Ezcurra (2011), "Is fiscal decentralization harmful for economic growth? Evidence from the OECD countries", Journal of Economic Geography 11, 619-643.

Solow R.M. (1957), "Technical Change and the Aggregate Production Function," The Review of Economics and Statistics 39, 312-320.

Van Ark B., M. O'Mahony and M.P. Timmer (2008), "The Productivity Gap between Europe and the United States; Trends and Causes," Journal of Economic Perspectives $22(1), 25-44$.

Vandenbussche J., P. Aghion and C. Meghir (2006), "Growth, distance to frontier and composition of human capital", Journal of Economic Growth 11(2), 97-127.

Vickers J. (1995), “Concepts of competition”, Oxford Economic Papers 47, 1-23. 
Winston C. (1993), "Economic deregulation: days of reckoning for microeconomists", Journal of Economic Literature XXXI, 1263-1289.

Wong W.K. (2006), "OECD Convergence; A Sectoral Decomposition Exercise," Economics Letters 93, 210-214. 


\begin{tabular}{|l|l|r|r|r|r|r|}
\hline \multicolumn{7}{|l|}{ Table 1. Summary statistics of the OECD data, 1980-2006, 1037 observations. } \\
\hline Variable & Labels & \multicolumn{1}{c}{ Mean } & \multicolumn{1}{c|}{ Median } & \multicolumn{1}{c|}{ Std Dev } & \multicolumn{1}{c|}{ Minimum } & \multicolumn{1}{c|}{ Maximum } \\
\hline Output & GDP & $614,060.009$ & $175,982.000$ & $1,419,307.953$ & $4,105.077$ & $11,314,700.000$ \\
\hline Energy & ENE & $3,687.184$ & $3,512.000$ & $2,207.038$ & 304.000 & $12,219.000$ \\
\hline Labor & LAB & 45.064 & 6.415 & 118.461 & 0.123 & 780.549 \\
\hline Capital & CAP & $130,606.662$ & $39,550.751$ & $281,730.872$ & 957.791 & $2,152,200.000$ \\
\hline lgdp & Log GDP & 12.102 & 12.078 & 1.571 & 8.320 & 16.242 \\
\hline lene & Log ENE & 7.991 & 8.164 & 0.741 & 5.717 & 9.411 \\
\hline lcap & Log CAP & 10.5952 & 10.5853 & 1.5561 & 6.8646 & 14.5820 \\
\hline lene & Log ENE & 7.991 & 8.164 & 0.741 & 5.717 & 9.411 \\
\hline Trend & T & 14.368 & 15.000 & 7.714 & 1.000 & 27.000 \\
\hline Credit & DCG & 94.369 & 86.170 & 56.816 & 8.200 & 442.620 \\
\hline Trade & TRD & 70.891 & 61.200 & 42.860 & 12.360 & 326.600 \\
\hline Net FDI & FDI & 11.144 & 1.260 & 54.103 & -15.130 & 522.220 \\
\hline Electricity & ELE & $26,7839.264$ & $82,075.000$ & $568,559.349$ & 0.000 & $4,268,380.000$ \\
\hline Listed comp. & LDC & 773.636 & 241.105 & $1,379.305$ & 9.000 & $8,851.000$ \\
\hline Gov. Cons. & GOV & 17.971 & 18.450 & 5.230 & 5.690 & 41.480 \\
\hline Computer & CPS & 32.770 & 31.450 & 12.032 & 0.000 & 77.030 \\
\hline Internet & INT & 7.796 & 1.560 & 19.961 & 0.000 & 208.000 \\
\hline Telephone & TEL & 34.676 & 31.092 & 29.372 & 0.000 & 590.710 \\
\hline
\end{tabular}




\begin{tabular}{|l|r|r|r|r|r|}
\hline \multicolumn{7}{|l|}{ Table 2.1 Correlation matrix of output and inputs } \\
\hline & GDP & Energy & Capital & Labor & Trend \\
\hline GDP & 1.000 & 0.246 & 0.966 & 0.196 & 0.081 \\
\hline & & 0.000 & 0.000 & 0.000 & 0.009 \\
\hline Energy & 0.246 & 1.000 & 0.187 & -0.299 & 0.108 \\
\hline & 0.000 & & 0.000 & 0.000 & 0.001 \\
\hline Capital & 0.966 & 0.187 & 1.000 & 0.266 & 0.093 \\
\hline & 0.000 & 0.000 & & 0.000 & 0.003 \\
\hline Labor & 0.196 & -0.299 & 0.266 & 1.000 & 0.037 \\
\hline & 0.000 & 0.000 & 0.000 & & 0.230 \\
\hline Trend & 0.081 & 0.108 & 0.093 & 0.037 & 1.000 \\
\hline & 0.009 & 0.001 & 0.003 & 0.230 & \\
\hline
\end{tabular}

\begin{tabular}{|l|r|r|r|r|r|r|r|r|r|r|r|}
\hline \multicolumn{2}{|l|}{ Table 2.2 Correlation matrix of output and technology shifters } \\
\hline & GDP & Credit & Trade & FDI & $\begin{array}{l}\text { Elect- } \\
\text { ricity }\end{array}$ & $\begin{array}{l}\text { Listed } \\
\text { Comp }\end{array}$ & $\begin{array}{l}\text { Gov- } \\
\text { cons }\end{array}$ & $\begin{array}{l}\text { lom- } \\
\text { puter }\end{array}$ & $\begin{array}{l}\text { Inter- } \\
\text { net }\end{array}$ & $\begin{array}{l}\text { Tele- } \\
\text { phone }\end{array}$ \\
\hline GDP & 1.000 & 0.594 & -0.322 & -0.076 & 0.922 & 0.745 & -0.069 & -0.048 & 0.784 & -0.099 \\
\hline & & 0.000 & 0.000 & 0.015 & 0.000 & 0.000 & 0.025 & 0.122 & 0.000 & 0.001 \\
\hline Credit & 0.594 & 1.000 & -0.137 & 0.010 & 0.438 & 0.376 & 0.087 & 0.014 & 0.436 & -0.146 \\
\hline & 0.000 &. & 0.000 & 0.747 & 0.000 & 0.000 & 0.005 & 0.645 & 0.000 & 0.000 \\
\hline Trade & -0.322 & -0.137 & 1.000 & 0.580 & -0.324 & -0.377 & 0.210 & 0.209 & -0.253 & -0.054 \\
\hline & 0.000 & 0.000 &. & 0.000 & 0.000 & 0.000 & 0.000 & 0.000 & 0.000 & 0.081 \\
\hline FDI & -0.076 & 0.010 & 0.580 & 1.000 & -0.083 & -0.092 & -0.050 & -0.084 & -0.068 & -0.053 \\
\hline & 0.015 & 0.747 & 0.000 &. & 0.008 & 0.003 & 0.106 & 0.007 & 0.029 & 0.089 \\
\hline Electricity & 0.922 & 0.438 & -0.324 & -0.083 & 1.000 & 0.766 & -0.075 & -0.091 & 0.778 & -0.084 \\
\hline & 0.000 & 0.000 & 0.000 & 0.008 &. & 0.000 & 0.016 & 0.004 & 0.000 & 0.007 \\
\hline List.comp & 0.745 & 0.376 & -0.377 & -0.092 & 0.766 & 1.000 & -0.135 & -0.089 & 0.601 & -0.032 \\
\hline & 0.000 & 0.000 & 0.000 & 0.003 & 0.000 & & 0.000 & 0.004 & 0.000 & 0.303 \\
\hline Gov. cons & -0.069 & 0.087 & 0.210 & -0.050 & -0.075 & -0.135 & 1.000 & 0.116 & -0.093 & -0.164 \\
\hline & 0.025 & 0.005 & 0.000 & 0.106 & 0.016 & 0.000 & & 0.000 & 0.003 & 0.000 \\
\hline Computer & -0.048 & 0.014 & 0.209 & -0.084 & -0.091 & -0.089 & 0.116 & 1.000 & -0.055 & 0.036 \\
\hline & 0.122 & 0.645 & 0.000 & 0.007 & 0.004 & 0.004 & 0.000 & & 0.076 & 0.246 \\
\hline Internet & 0.784 & 0.436 & -0.253 & -0.068 & 0.778 & 0.601 & -0.093 & -0.055 & 1.000 & -0.069 \\
\hline & 0.000 & 0.000 & 0.000 & 0.029 & 0.000 & 0.000 & 0.003 & 0.076 &. & 0.027 \\
\hline Telephone & -0.099 & -0.146 & -0.054 & -0.053 & -0.084 & -0.032 & -0.164 & 0.036 & -0.069 & 1.000 \\
\hline & 0.001 & 0.000 & 0.081 & 0.089 & 0.007 & 0.303 & 0.000 & 0.246 & 0.027 &. \\
\hline
\end{tabular}




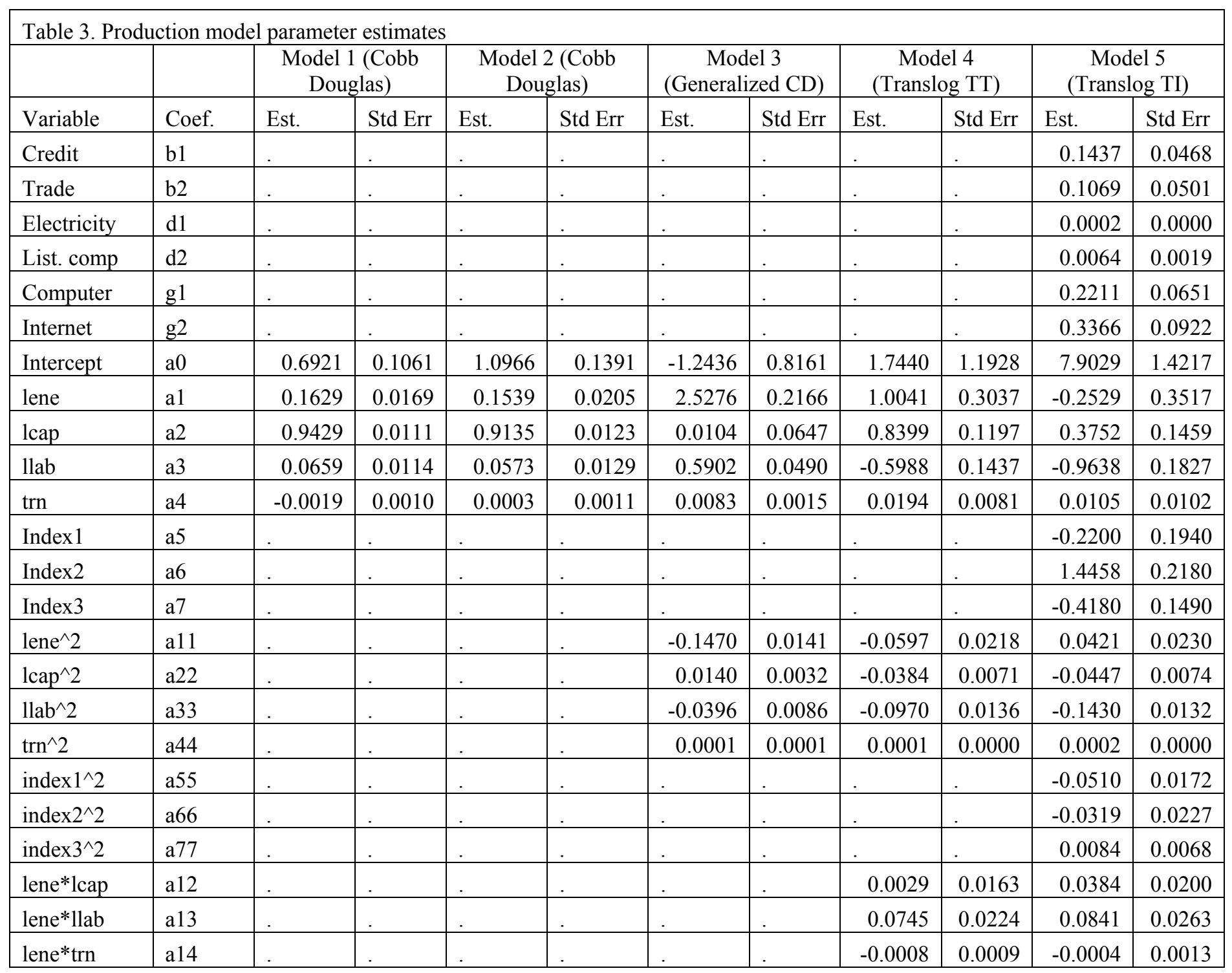




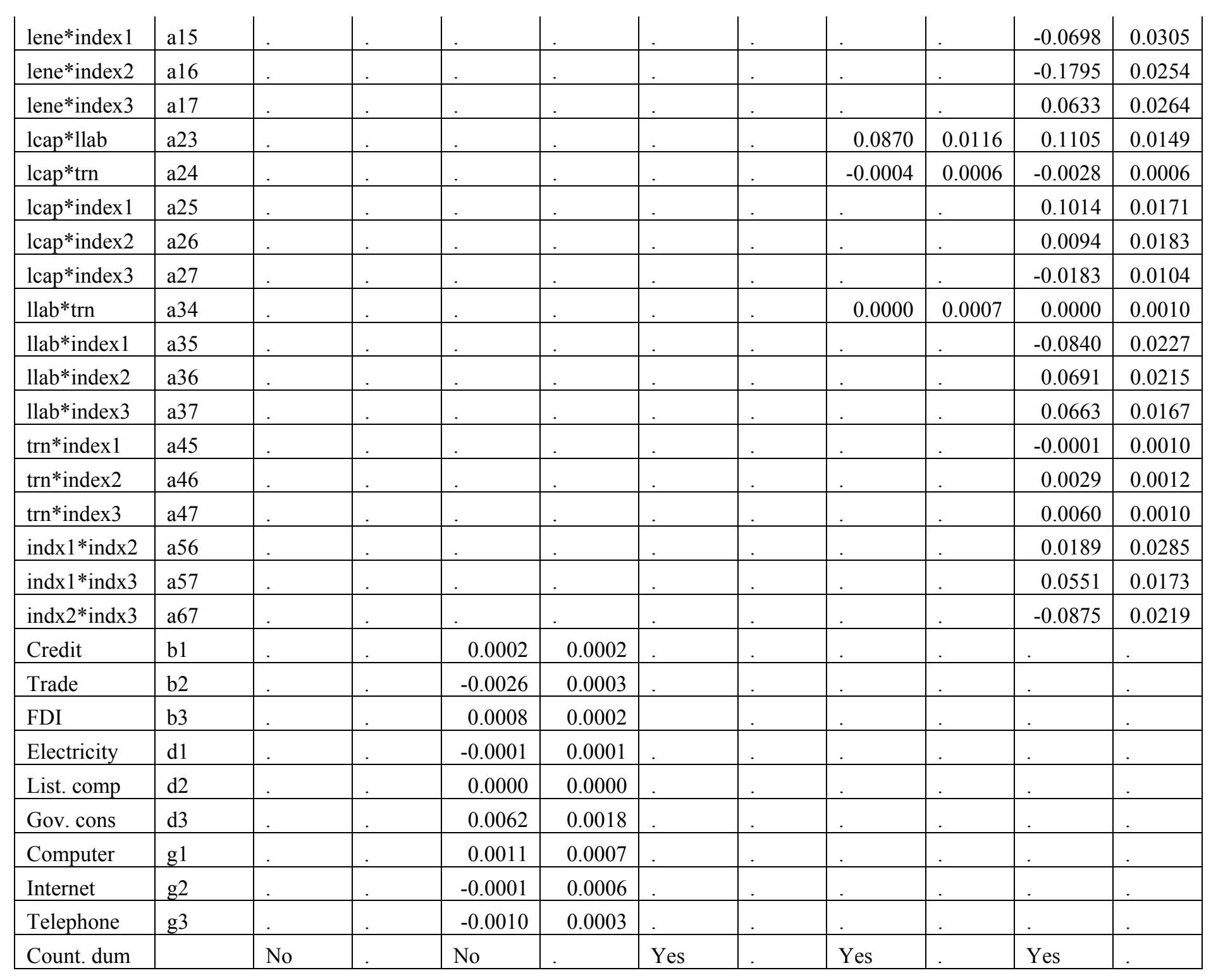




\begin{tabular}{|l|l|r|l|r|r|r|l|r|r|r|r|} 
Obs & obs & 1,037 &. & 1,037 &. & 1,037 &. & 1,037 &. & 1,037 &. \\
\hline RMSE & Sigma & 0.2479 &. & 0.2350 &. & 0.0718 &. & 0.0665 &. & 0.0560 &. \\
\hline F-value & F-value & 10,145 &. & 3,483 &. & &. & &. & &. \\
\hline Iterations & Iter & 1 &. & 1 &. & 1 &. & 1 &. & 43 &. \\
\hline R2 adjusted & R2 Adj & 0.9751 &. & 0.9776 &. & 0.9979 &. & 0.9982 &. & 0.9987 &. \\
\hline
\end{tabular}




\begin{tabular}{|c|c|c|c|c|c|c|c|c|c|c|}
\hline \multirow[b]{2}{*}{$\begin{array}{l}\text { Code/ } \\
\text { Year }\end{array}$} & \multicolumn{3}{|c|}{ Technology index values } & \multicolumn{3}{|c|}{$\begin{array}{l}\text { Marginal effect of } \\
\text { technology indices }\end{array}$} & \multicolumn{4}{|c|}{ Input elasticities and returns to scale } \\
\hline & index1c & index $2 c$ & index $3 c$ & $\begin{array}{l}\text { ME } \\
\text { index 1 }\end{array}$ & $\begin{array}{l}\text { ME } \\
\text { index2 }\end{array}$ & $\begin{array}{l}\text { ME } \\
\text { index3 }\end{array}$ & Energy & Capital & Labor & RTS \\
\hline AUS & 15.503 & 63.413 & 21.515 & 0.107 & -0.276 & -0.017 & 0.333 & 0.159 & 0.642 & 1.134 \\
\hline AUT & 25.664 & 30.947 & 25.632 & 0.080 & -0.225 & 0.007 & 0.300 & 0.155 & 0.690 & 1.145 \\
\hline BEL & 37.445 & 38.661 & 22.611 & 0.011 & -0.285 & 0.035 & 0.277 & 0.216 & 0.674 & 1.166 \\
\hline BRA & 15.686 & 76.420 & 27.160 & 0.086 & 0.146 & -0.002 & 0.356 & 0.302 & -0.048 & 0.610 \\
\hline CAN & 26.739 & 100.000 & 22.990 & 0.038 & -0.357 & -0.006 & 0.242 & 0.262 & 0.580 & 1.083 \\
\hline $\mathrm{CHE}$ & 33.238 & 25.850 & 18.192 & 0.067 & -0.182 & 0.028 & 0.313 & 0.153 & 0.676 & 1.143 \\
\hline $\mathrm{CHL}$ & 22.403 & 19.294 & 22.462 & -0.017 & 0.019 & 0.020 & 0.276 & 0.258 & 0.317 & 0.851 \\
\hline $\mathrm{CHN}$ & 19.936 & 98.893 & 41.532 & 0.023 & 0.248 & 0.053 & 0.400 & 0.487 & -0.530 & 0.357 \\
\hline $\mathrm{CZE}$ & 24.881 & 39.377 & 30.844 & -0.034 & -0.259 & 0.068 & 0.281 & 0.260 & 0.542 & 1.082 \\
\hline DEU & 23.392 & 100.000 & 27.316 & 0.134 & -0.191 & -0.002 & 0.340 & 0.228 & 0.402 & 0.970 \\
\hline DNK & 22.045 & 34.727 & 17.719 & 0.066 & -0.241 & -0.027 & 0.245 & 0.145 & 0.737 & 1.127 \\
\hline ESP & 22.392 & 63.035 & 28.751 & 0.124 & -0.106 & -0.001 & 0.337 & 0.199 & 0.419 & 0.954 \\
\hline EST & 27.283 & 21.068 & 18.238 & -0.141 & -0.339 & 0.001 & 0.113 & 0.266 & 0.767 & 1.146 \\
\hline FIN & 17.343 & 35.448 & 23.351 & 0.059 & -0.364 & -0.007 & 0.297 & 0.143 & 0.822 & 1.262 \\
\hline FRA & 21.138 & 98.333 & 25.626 & 0.130 & -0.198 & -0.018 & 0.310 & 0.211 & 0.459 & 0.979 \\
\hline GBR & 23.475 & 99.594 & 21.235 & 0.090 & -0.148 & 0.001 & 0.318 & 0.244 & 0.368 & 0.931 \\
\hline GRC & 15.804 & 23.967 & 19.784 & 0.111 & -0.097 & -0.016 & 0.335 & 0.124 & 0.584 & 1.044 \\
\hline HUN & 25.072 & 17.821 & 27.775 & -0.058 & -0.144 & 0.075 & 0.347 & 0.276 & 0.432 & 1.055 \\
\hline IDN & 11.988 & 22.212 & 32.365 & 0.025 & 0.299 & 0.093 & 0.546 & 0.343 & -0.293 & 0.596 \\
\hline IND & 10.073 & 92.628 & 34.460 & 0.064 & 0.356 & -0.006 & 0.374 & 0.418 & -0.517 & 0.275 \\
\hline IRL & 28.440 & 21.233 & 26.592 & 0.044 & -0.253 & -0.004 & 0.242 & 0.148 & 0.789 & 1.178 \\
\hline ISL & 20.845 & 22.649 & 13.618 & -0.055 & -0.581 & -0.086 & 0.027 & 0.102 & 1.294 & 1.424 \\
\hline ISR & 25.668 & 40.421 & 19.470 & 0.098 & -0.220 & -0.073 & 0.142 & 0.120 & 0.804 & 1.066 \\
\hline ITA & 18.578 & 71.516 & 28.121 & 0.170 & -0.105 & -0.006 & 0.381 & 0.170 & 0.420 & 0.971 \\
\hline JPN & 45.381 & 100.000 & 32.829 & 0.174 & -0.141 & 0.001 & 0.300 & 0.240 & 0.355 & 0.896 \\
\hline KOR & 18.246 & 55.240 & 35.489 & 0.126 & -0.103 & 0.022 & 0.408 & 0.202 & 0.373 & 0.983 \\
\hline LUX & 100.000 & 16.692 & 17.310 & -0.269 & -0.512 & 0.092 & -0.058 & 0.328 & 1.092 & 1.362 \\
\hline MEX & 13.401 & 43.903 & 20.128 & 0.111 & 0.070 & 0.014 & 0.425 & 0.218 & 0.167 & 0.811 \\
\hline NLD & 31.941 & 42.674 & 20.896 & 0.028 & -0.225 & 0.041 & 0.318 & 0.223 & 0.568 & 1.109 \\
\hline NOR & 20.435 & 46.766 & 21.524 & 0.082 & -0.352 & -0.044 & 0.216 & 0.127 & 0.869 & 1.212 \\
\hline NZL & 20.522 & 26.835 & 15.533 & -0.015 & -0.265 & -0.016 & 0.211 & 0.188 & 0.730 & 1.129 \\
\hline POL & 13.346 & 51.978 & 25.053 & 0.025 & -0.093 & 0.043 & 0.349 & 0.258 & 0.284 & 0.891 \\
\hline PRT & 22.920 & 24.470 & 20.208 & 0.047 & -0.055 & 0.005 & 0.291 & 0.195 & 0.472 & 0.958 \\
\hline RUS & 10.949 & 95.616 & 16.617 & -0.020 & -0.140 & 0.022 & 0.305 & 0.358 & 0.104 & 0.766 \\
\hline
\end{tabular}




\begin{tabular}{|c|c|c|c|c|c|c|c|c|c|c|}
\hline SVK & 23.963 & 29.945 & 31.594 & -0.064 & -0.289 & 0.036 & 0.230 & 0.267 & 0.607 & 1.103 \\
\hline SVN & 20.326 & 22.499 & 37.414 & 0.010 & -0.317 & 0.002 & 0.186 & 0.155 & 0.836 & 1.177 \\
\hline SWE & 26.224 & 60.297 & 21.137 & 0.025 & -0.323 & -0.007 & 0.228 & 0.212 & 0.696 & 1.135 \\
\hline TUR & 10.810 & 30.248 & 24.564 & 0.108 & 0.136 & -0.003 & 0.413 & 0.206 & 0.136 & 0.756 \\
\hline USA & 31.271 & 100.000 & 43.276 & 0.146 & -0.329 & -0.034 & 0.241 & 0.308 & 0.358 & 0.907 \\
\hline ZAF & 25.983 & 61.462 & 18.618 & -0.091 & -0.099 & 0.032 & 0.233 & 0.371 & 0.213 & 0.817 \\
\hline access & 22.161 & 42.290 & 21.947 & -0.015 & -0.259 & -0.017 & 0.175 & 0.219 & 0.657 & 1.051 \\
\hline enhanc & 16.733 & 70.323 & 30.827 & 0.021 & 0.190 & 0.034 & 0.382 & 0.384 & -0.235 & 0.531 \\
\hline member & 26.075 & 49.704 & 24.187 & 0.053 & -0.209 & 0.005 & 0.282 & 0.206 & 0.570 & 1.058 \\
\hline 1980 & 19.293 & 44.574 & 27.706 & 0.074 & -0.182 & -0.082 & 0.324 & 0.234 & 0.488 & 1.045 \\
\hline 1981 & 19.725 & 45.420 & 25.871 & 0.071 & -0.170 & -0.078 & 0.314 & 0.234 & 0.480 & 1.028 \\
\hline 1982 & 20.475 & 45.966 & 28.143 & 0.065 & -0.171 & -0.069 & 0.311 & 0.240 & 0.472 & 1.023 \\
\hline 1983 & 20.647 & 46.367 & 24.649 & 0.052 & -0.157 & -0.063 & 0.300 & 0.246 & 0.455 & 1.001 \\
\hline 1984 & 21.555 & 46.517 & 25.630 & 0.052 & -0.168 & -0.053 & 0.303 & 0.243 & 0.468 & 1.014 \\
\hline 1985 & 21.537 & 47.266 & 25.340 & 0.051 & -0.169 & -0.047 & 0.301 & 0.241 & 0.470 & 1.013 \\
\hline 1986 & 21.339 & 47.617 & 25.423 & 0.051 & -0.170 & -0.040 & 0.303 & 0.239 & 0.472 & 1.014 \\
\hline 1987 & 21.549 & 48.389 & 24.631 & 0.050 & -0.169 & -0.034 & 0.300 & 0.237 & 0.473 & 1.010 \\
\hline 1988 & 22.302 & 48.615 & 25.377 & 0.052 & -0.170 & -0.026 & 0.304 & 0.233 & 0.478 & 1.015 \\
\hline 1989 & 22.663 & 47.785 & 26.225 & 0.052 & -0.168 & -0.011 & 0.320 & 0.233 & 0.468 & 1.021 \\
\hline 1990 & 21.952 & 49.856 & 24.489 & 0.046 & -0.173 & -0.014 & 0.300 & 0.233 & 0.477 & 1.010 \\
\hline 1991 & 22.145 & 50.521 & 22.974 & 0.037 & -0.167 & -0.008 & 0.292 & 0.238 & 0.466 & 0.996 \\
\hline 1992 & 22.374 & 51.305 & 23.271 & 0.031 & -0.163 & -0.003 & 0.282 & 0.241 & 0.459 & 0.982 \\
\hline 1993 & 22.965 & 51.988 & 23.293 & 0.028 & -0.163 & 0.002 & 0.275 & 0.242 & 0.458 & 0.976 \\
\hline 1994 & 22.848 & 52.258 & 23.536 & 0.033 & -0.162 & 0.007 & 0.278 & 0.235 & 0.464 & 0.977 \\
\hline 1995 & 23.293 & 52.886 & 22.801 & 0.037 & -0.160 & 0.012 & 0.276 & 0.229 & 0.470 & 0.975 \\
\hline 1996 & 23.414 & 53.557 & 23.610 & 0.041 & -0.166 & 0.019 & 0.280 & 0.225 & 0.479 & 0.983 \\
\hline 1997 & 24.460 & 53.957 & 23.505 & 0.042 & -0.163 & 0.027 & 0.279 & 0.222 & 0.481 & 0.982 \\
\hline 1998 & 25.838 & 54.384 & 24.155 & 0.038 & -0.161 & 0.037 & 0.276 & 0.224 & 0.478 & 0.978 \\
\hline 1999 & 28.081 & 55.036 & 23.045 & 0.030 & -0.155 & 0.045 & 0.267 & 0.229 & 0.470 & 0.966 \\
\hline 2000 & 30.703 & 55.708 & 24.963 & 0.032 & -0.157 & 0.054 & 0.266 & 0.228 & 0.475 & 0.969 \\
\hline 2001 & 29.700 & 56.316 & 25.086 & 0.031 & -0.157 & 0.060 & 0.265 & 0.226 & 0.475 & 0.966 \\
\hline 2002 & 28.857 & 57.500 & 24.414 & 0.030 & -0.152 & 0.062 & 0.259 & 0.224 & 0.472 & 0.955 \\
\hline 2003 & 28.435 & 58.155 & 22.979 & 0.031 & -0.148 & 0.065 & 0.257 & 0.218 & 0.475 & 0.950 \\
\hline 2004 & 28.789 & 58.586 & 24.423 & 0.038 & -0.153 & 0.073 & 0.262 & 0.212 & 0.485 & 0.959 \\
\hline 2005 & 30.721 & 58.777 & 26.200 & 0.040 & -0.153 & 0.082 & 0.263 & 0.210 & 0.489 & 0.961 \\
\hline 2006 & 32.641 & 52.577 & 30.635 & 0.052 & -0.122 & 0.102 & 0.293 & 0.202 & 0.465 & 0.961 \\
\hline Mean & 24.523 & 51.752 & 24.859 & 0.043 & -0.162 & 0.007 & 0.286 & 0.230 & 0.473 & 0.989 \\
\hline Std Dev & 15.642 & 30.437 & 10.470 & 0.094 & 0.205 & 0.684 & 0.115 & 0.089 & 0.378 & 0.242 \\
\hline
\end{tabular}




\begin{tabular}{|c|c|c|c|c|c|c|c|c|c|c|}
\hline & \multicolumn{4}{|c|}{ TFP growth and its components } & \multicolumn{3}{|c|}{$\begin{array}{l}\text { Elasticity of technology } \\
\text { indices }\end{array}$} & \multicolumn{3}{|c|}{$\begin{array}{c}\text { TFP growth components } \\
\text { share }\end{array}$} \\
\hline & scale & index & tc & $\mathrm{tfp}$ & $\begin{array}{c}\text { sindex } \\
1\end{array}$ & $\begin{array}{l}\text { sindex } \\
2\end{array}$ & $\begin{array}{c}\text { sindex } \\
3\end{array}$ & sscale & sindex & stc \\
\hline & & 0.982 & 0.169 & 0.000 & 0.000 & 0.000 & 0.214 & 0.015 & 0.416 & 0.000 \\
\hline \multirow[t]{2}{*}{ index } & -0.001 & 1.000 & 0.073 & 0.813 & 0.007 & -0.048 & 0.064 & -0.039 & -0.006 & 0.046 \\
\hline & 0.982 & & 0.019 & 0.000 & 0.831 & 0.121 & 0.038 & 0.208 & 0.854 & 0.135 \\
\hline \multirow[t]{2}{*}{ tc } & -0.043 & 0.073 & 1.000 & 0.199 & 0.091 & -0.175 & 0.149 & 0.010 & -0.007 & -0.043 \\
\hline & 0.169 & 0.019 & & 0.000 & 0.003 & .000 & 0.000 & 0.760 & 0.827 & 0.168 \\
\hline \multirow[t]{2}{*}{$\mathrm{tfp}$} & 0.377 & 0.813 & 0.199 & 1.000 & 0.104 & -0.125 & 0.057 & -0.079 & 0.018 & 0.124 \\
\hline & 0.000 & 0.000 & 0.000 & & 0.001 & 0.000 & 0.068 & 0.011 & 0.569 & 0.000 \\
\hline \multirow[t]{2}{*}{ sindex 1} & 0.230 & 0.007 & 0.091 & 0.104 & 1.000 & -0.756 & -0.128 & 0.006 & 0.026 & -0.029 \\
\hline & 0.000 & 0.831 & 0.003 & 0.001 & & 0.000 & 0.000 & 0.845 & 0.406 & 0.354 \\
\hline \multirow[t]{2}{*}{ sindex 2} & -0.168 & -0.048 & -0.175 & -0.125 & -0.756 & 1.000 & -0.553 & 0.021 & -0.047 & 0.023 \\
\hline & 0.000 & 0.121 & 0.000 & 0.000 & 0.000 & & 0.000 & 0.497 & 0.133 & 0.459 \\
\hline \multirow[t]{2}{*}{ sindex 3} & -0.039 & 0.064 & 0.149 & 0.057 & -0.128 & -0.553 & 1.000 & -0.040 & 0.038 & 0.002 \\
\hline & 0.214 & 0.038 & 0.000 & 0.068 & 0.000 & 0.000 & & 0.201 & 0.223 & 0.953 \\
\hline \multirow[t]{2}{*}{ sscale } & -0.076 & -0.039 & 0.010 & -0.079 & 0.006 & 0.021 & -0.040 & 1.000 & -0.285 & -0.322 \\
\hline & 0.015 & 0.208 & 0.760 & 0.011 & 0.845 & 0.497 & 0.201 & & 0.000 & 0.000 \\
\hline \multirow[t]{2}{*}{ sindex } & -0.025 & -0.006 & -0.007 & 0.018 & 0.026 & -0.047 & 0.038 & -0.285 & 1.000 & -0.646 \\
\hline & 0.416 & 0.854 & 0.827 & 0.569 & 0.406 & 0.133 & 0.223 & 0.000 & & 0.000 \\
\hline \multirow[t]{2}{*}{ stc } & 0.183 & 0.046 & -0.043 & 0.124 & -0.029 & 0.023 & 0.002 & -0.322 & -0.646 & 1.000 \\
\hline & 0.000 & 0.135 & 0.168 & 0.000 & 0.354 & 0.459 & 0.953 & 0.000 & 0.000 & \\
\hline
\end{tabular}




\begin{tabular}{|c|c|c|c|c|c|c|c|c|c|c|}
\hline \multirow[b]{2}{*}{ code } & \multicolumn{4}{|c|}{ TFG growth and its components } & \multicolumn{3}{|c|}{$\begin{array}{l}\text { Elasticity of technology } \\
\text { indices }\end{array}$} & \multicolumn{3}{|c|}{$\begin{array}{c}\text { TFP growth components } \\
\text { share }\end{array}$} \\
\hline & scale & tc & index & $\mathrm{tfp}$ & sindex 1 & sindex 2 & sindex 3 & sindex & stc & sscale \\
\hline AUT & 0.001 & 0.014 & 0.001 & 0.017 & 0.317 & 0.377 & 0.306 & -0.146 & 0.969 & 0.020 \\
\hline BEL & 0.002 & 0.013 & -0.002 & 0.013 & 0.376 & 0.395 & 0.228 & 0.019 & 0.724 & 0.055 \\
\hline BRA & -0.002 & 0.015 & 0.002 & 0.016 & 0.130 & 0.644 & 0.225 & 0.288 & 0.652 & -0.033 \\
\hline CAN & 0.001 & 0.015 & 0.001 & 0.018 & 0.186 & 0.663 & 0.151 & 0.070 & 0.888 & 0.047 \\
\hline CHE & 0.002 & 0.010 & 0.003 & 0.014 & 0.433 & 0.336 & 0.231 & 0.364 & 0.235 & 0.188 \\
\hline CHL & -0.003 & 0.016 & -0.003 & 0.010 & 0.352 & 0.302 & 0.346 & -0.144 & 0.986 & 0.025 \\
\hline $\mathrm{CHN}$ & -0.028 & 0.020 & 0.008 & 0.001 & 0.138 & 0.585 & 0.278 & -0.105 & -0.561 & 1.170 \\
\hline CZE & 0.001 & 0.020 & 0.007 & 0.027 & 0.266 & 0.419 & 0.315 & 0.136 & 0.590 & 0.006 \\
\hline DEU & 0.000 & 0.013 & 0.005 & 0.017 & 0.159 & 0.663 & 0.178 & 0.249 & 0.704 & -0.007 \\
\hline DNK & 0.001 & 0.013 & 0.003 & 0.017 & 0.298 & 0.469 & 0.233 & 0.113 & 0.648 & -0.024 \\
\hline ESP & -0.001 & 0.014 & 0.003 & 0.017 & 0.197 & 0.557 & 0.247 & -0.174 & 1.068 & -0.117 \\
\hline EST & 0.000 & 0.018 & -0.002 & 0.017 & 0.423 & 0.312 & 0.265 & 0.345 & 0.600 & -0.036 \\
\hline FIN & 0.002 & 0.015 & -0.001 & 0.016 & 0.230 & 0.466 & 0.304 & 0.000 & 0.621 & 0.336 \\
\hline FRA & 0.000 & 0.013 & 0.003 & 0.015 & 0.147 & 0.680 & 0.174 & -0.067 & 0.952 & -0.033 \\
\hline GBR & -0.001 & 0.012 & 0.006 & 0.017 & 0.167 & 0.685 & 0.148 & 0.155 & 0.865 & -0.049 \\
\hline GRC & 0.002 & 0.012 & 0.004 & 0.018 & 0.270 & 0.413 & 0.318 & -0.221 & 0.923 & 0.160 \\
\hline HUN & 0.000 & 0.016 & 0.004 & 0.020 & 0.367 & 0.259 & 0.374 & 0.152 & 0.763 & -0.053 \\
\hline IDN & -0.004 & 0.016 & 0.016 & 0.029 & 0.189 & 0.354 & 0.458 & 0.573 & 0.186 & -0.066 \\
\hline IND & -0.018 & 0.020 & 0.006 & 0.008 & 0.076 & 0.676 & 0.248 & -0.261 & -0.285 & 0.775 \\
\hline IRL & 0.006 & 0.016 & 0.004 & 0.026 & 0.397 & 0.269 & 0.335 & 0.162 & 0.609 & 0.199 \\
\hline ISL & 0.012 & 0.018 & -0.019 & 0.011 & 0.357 & 0.403 & 0.240 & 0.374 & 0.144 & 0.106 \\
\hline ISR & 0.002 & 0.015 & 0.001 & 0.018 & 0.287 & 0.480 & 0.232 & -0.087 & 0.847 & 0.147 \\
\hline ITA & 0.000 & 0.012 & 0.004 & 0.016 & 0.157 & 0.608 & 0.235 & 0.067 & 0.855 & -0.013 \\
\hline JPN & 0.000 & 0.012 & 0.007 & 0.019 & 0.258 & 0.560 & 0.182 & 0.282 & 0.794 & -0.076 \\
\hline KOR & 0.000 & 0.015 & 0.001 & 0.017 & 0.166 & 0.535 & 0.299 & -0.124 & 0.759 & 0.205 \\
\hline LUX & 0.010 & 0.017 & 0.003 & 0.030 & 0.747 & 0.124 & 0.129 & 0.305 & 0.194 & 0.321 \\
\hline MEX & -0.002 & 0.011 & 0.004 & 0.013 & 0.173 & 0.572 & 0.255 & 0.355 & 0.521 & -0.121 \\
\hline NLD & 0.001 & 0.012 & 0.002 & 0.016 & 0.337 & 0.445 & 0.218 & -0.096 & 0.950 & 0.107 \\
\hline NOR & 0.003 & 0.015 & 0.000 & 0.017 & 0.231 & 0.531 & 0.238 & 0.058 & 0.625 & 0.208 \\
\hline NZL & 0.002 & 0.014 & -0.002 & 0.015 & 0.331 & 0.425 & 0.244 & -0.358 & 1.084 & 0.275 \\
\hline POL & -0.001 & 0.018 & 0.004 & 0.021 & 0.152 & 0.576 & 0.272 & 0.134 & 0.808 & -0.038 \\
\hline PRT & 0.000 & 0.014 & 0.001 & 0.015 & 0.340 & 0.366 & 0.294 & 0.050 & 0.802 & 0.004 \\
\hline RUS & -0.001 & 0.016 & -0.058 & -0.003 & 0.094 & 0.758 & 0.148 & 0.388 & 0.596 & 0.083 \\
\hline SVK & 0.001 & 0.021 & 0.003 & 0.024 & 0.285 & 0.351 & 0.364 & 0.301 & 0.606 & -0.002 \\
\hline
\end{tabular}




\begin{tabular}{|c|c|c|c|c|c|c|c|c|c|c|}
\hline SVN & 0.003 & 0.023 & 0.007 & 0.033 & 0.262 & 0.293 & 0.445 & -0.152 & 1.004 & 0.045 \\
\hline SWE & 0.001 & 0.015 & -0.001 & 0.015 & 0.245 & 0.560 & 0.195 & -0.104 & 0.855 & -0.046 \\
\hline TUR & -0.005 & 0.013 & 0.016 & 0.024 & 0.176 & 0.502 & 0.322 & 0.329 & 0.080 & 0.155 \\
\hline USA & -0.001 & 0.016 & 0.005 & 0.020 & 0.184 & 0.572 & 0.245 & 0.172 & 0.876 & -0.131 \\
\hline ZAF & -0.004 & 0.016 & -0.002 & 0.010 & 0.247 & 0.579 & 0.174 & 0.388 & 0.330 & 0.070 \\
\hline Access & 0.000 & 0.016 & -0.038 & 0.005 & 0.163 & 0.651 & 0.186 & 0.229 & 0.684 & 0.098 \\
\hline Enhance & -0.016 & 0.018 & 0.006 & 0.009 & 0.135 & 0.602 & 0.263 & 0.055 & -0.062 & 0.607 \\
\hline Member & 0.000 & 0.014 & 0.005 & 0.018 & 0.204 & 0.578 & 0.218 & 0.154 & 0.822 & -0.058 \\
\hline 1980 & 0.000 & 0.008 & 0.000 & 0.008 & 0.154 & 0.587 & 0.259 & 0.000 & 1.000 & 0.000 \\
\hline 1981 & 0.001 & 0.009 & 0.001 & 0.011 & 0.156 & 0.589 & 0.255 & 0.198 & 0.666 & 0.015 \\
\hline 1982 & 0.000 & 0.010 & 0.005 & 0.014 & 0.159 & 0.586 & 0.255 & 0.451 & 0.558 & -0.088 \\
\hline 1983 & 0.000 & 0.010 & 0.005 & 0.015 & 0.163 & 0.591 & 0.246 & 0.051 & 0.766 & 0.071 \\
\hline 1984 & -0.002 & 0.010 & 0.000 & 0.008 & 0.164 & 0.587 & 0.248 & 0.209 & 0.753 & -0.046 \\
\hline 1985 & -0.003 & 0.011 & 0.003 & 0.011 & 0.166 & 0.589 & 0.245 & 0.367 & 0.709 & -0.054 \\
\hline 1986 & 0.000 & 0.011 & 0.006 & 0.017 & 0.170 & 0.589 & 0.241 & 0.337 & 0.596 & 0.022 \\
\hline 1987 & -0.002 & 0.011 & 0.005 & 0.014 & 0.176 & 0.587 & 0.237 & 0.163 & 0.599 & 0.114 \\
\hline 1988 & -0.003 & 0.012 & 0.003 & 0.012 & 0.180 & 0.584 & 0.237 & 0.220 & 0.714 & 0.020 \\
\hline 1989 & -0.001 & 0.012 & 0.005 & 0.016 & 0.184 & 0.576 & 0.240 & 0.263 & 0.800 & -0.071 \\
\hline 1990 & -0.001 & 0.009 & 0.006 & 0.023 & 0.196 & 0.645 & 0.159 & 0.446 & 0.440 & 0.015 \\
\hline 1991 & 0.001 & 0.010 & -0.002 & 0.010 & 0.195 & 0.640 & 0.164 & -0.261 & 1.125 & 0.080 \\
\hline 1992 & -0.003 & 0.011 & 0.002 & 0.010 & 0.199 & 0.637 & 0.164 & -0.124 & 1.074 & -0.542 \\
\hline 1993 & -0.005 & 0.011 & 0.002 & 0.007 & 0.203 & 0.636 & 0.161 & 0.097 & 1.212 & -0.460 \\
\hline 1994 & -0.005 & 0.012 & -0.002 & 0.004 & 0.202 & 0.636 & 0.162 & 0.518 & -0.079 & 0.553 \\
\hline 1995 & -0.003 & 0.013 & 0.000 & 0.010 & 0.205 & 0.628 & 0.167 & 0.040 & 0.938 & -0.034 \\
\hline 1996 & -0.003 & 0.014 & 0.000 & 0.011 & 0.204 & 0.614 & 0.182 & -0.078 & 1.163 & -0.215 \\
\hline 1997 & -0.003 & 0.014 & 0.003 & 0.015 & 0.206 & 0.606 & 0.189 & 0.043 & 1.074 & -0.151 \\
\hline 1998 & 0.000 & 0.016 & 0.007 & 0.023 & 0.209 & 0.583 & 0.207 & 0.278 & 0.738 & -0.041 \\
\hline 1999 & -0.002 & 0.016 & 0.007 & 0.021 & 0.217 & 0.571 & 0.212 & 0.263 & 0.579 & 0.101 \\
\hline 2000 & -0.003 & 0.017 & 0.006 & 0.021 & 0.216 & 0.554 & 0.230 & 0.101 & 0.920 & -0.078 \\
\hline 2001 & 0.000 & 0.018 & 0.010 & 0.028 & 0.220 & 0.543 & 0.237 & 0.200 & 0.405 & 0.080 \\
\hline 2002 & -0.002 & 0.019 & -0.005 & 0.012 & 0.215 & 0.549 & 0.236 & -0.265 & 1.045 & 0.121 \\
\hline 2003 & -0.005 & 0.019 & 0.003 & 0.017 & 0.217 & 0.550 & 0.233 & 0.063 & 0.653 & 0.122 \\
\hline 2004 & -0.007 & 0.020 & 0.007 & 0.021 & 0.214 & 0.541 & 0.245 & 0.131 & 0.745 & -0.001 \\
\hline 2005 & -0.004 & 0.021 & 0.011 & 0.028 & 0.213 & 0.523 & 0.264 & 0.183 & 0.506 & 0.104 \\
\hline 2006 & 0.010 & 0.022 & 0.019 & 0.051 & 0.214 & 0.492 & 0.293 & 0.283 & 0.559 & 0.153 \\
\hline Mean & -0.001 & 0.001 & 0.014 & 0.015 & 0.255 & 0.484 & 0.261 & 0.098 & 0.107 & 0.636 \\
\hline Std Dev. & 0.014 & 0.035 & 0.004 & 0.029 & 0.129 & 0.153 & 0.101 & 0.659 & 0.933 & 0.981 \\
\hline
\end{tabular}


Figure 1. Development of TFP growth and its components, 1980-2006.

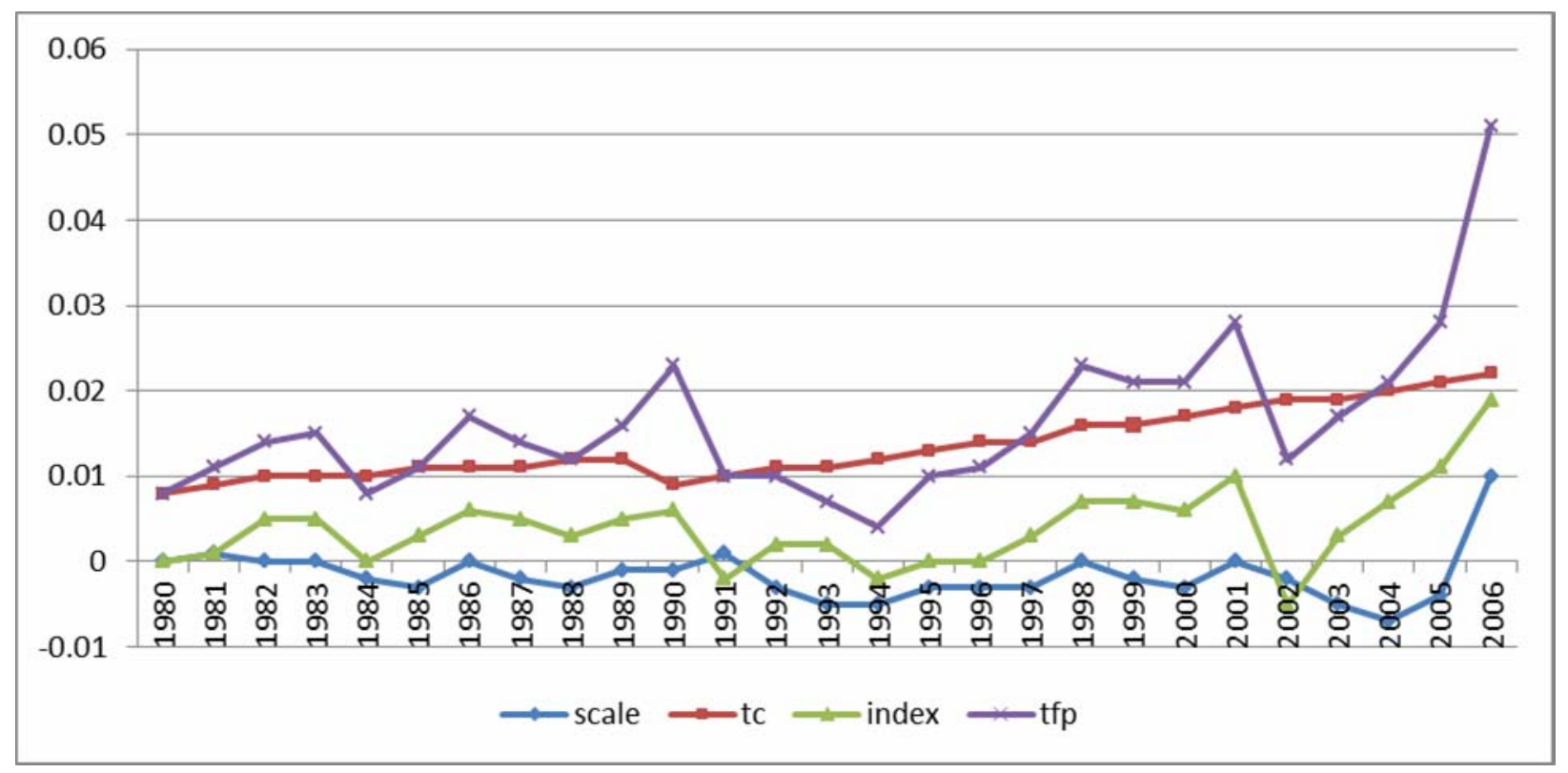

Figure 2. Development of the TFP growth components share, 1980-2006.

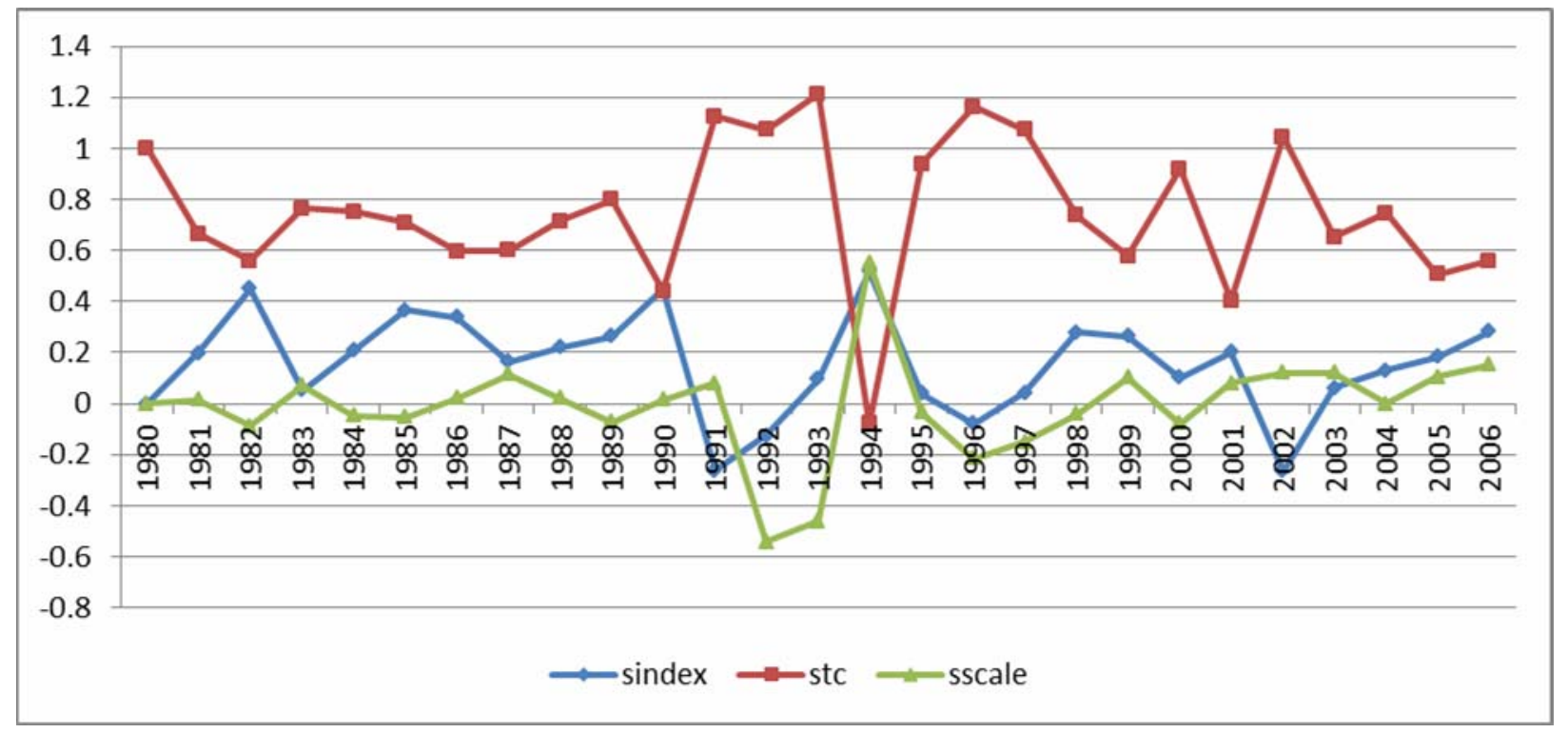


Figure 3. Development of RTS and input elasticities, 1980-2006.

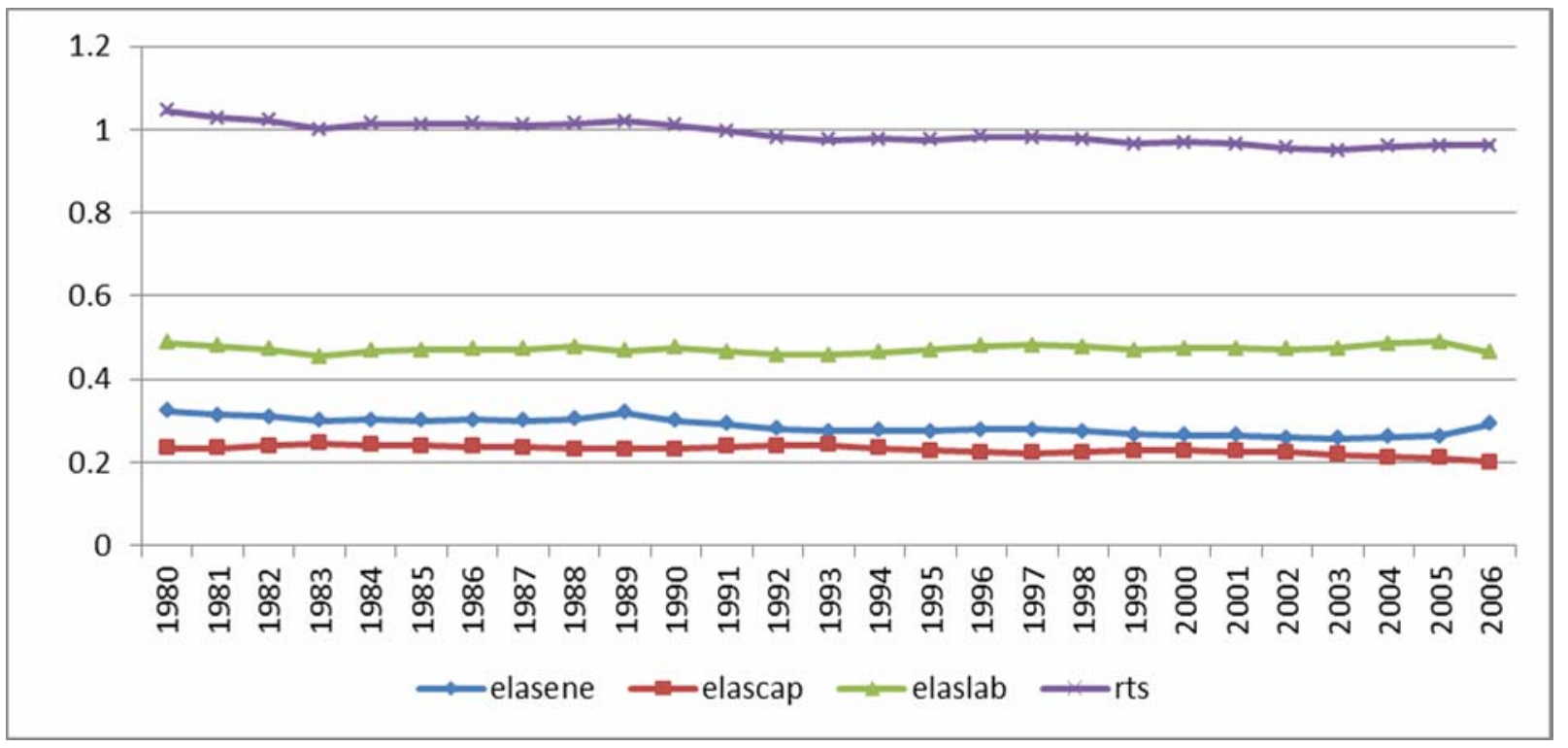

Figure 4. Development of TFP growth and its components across countries.

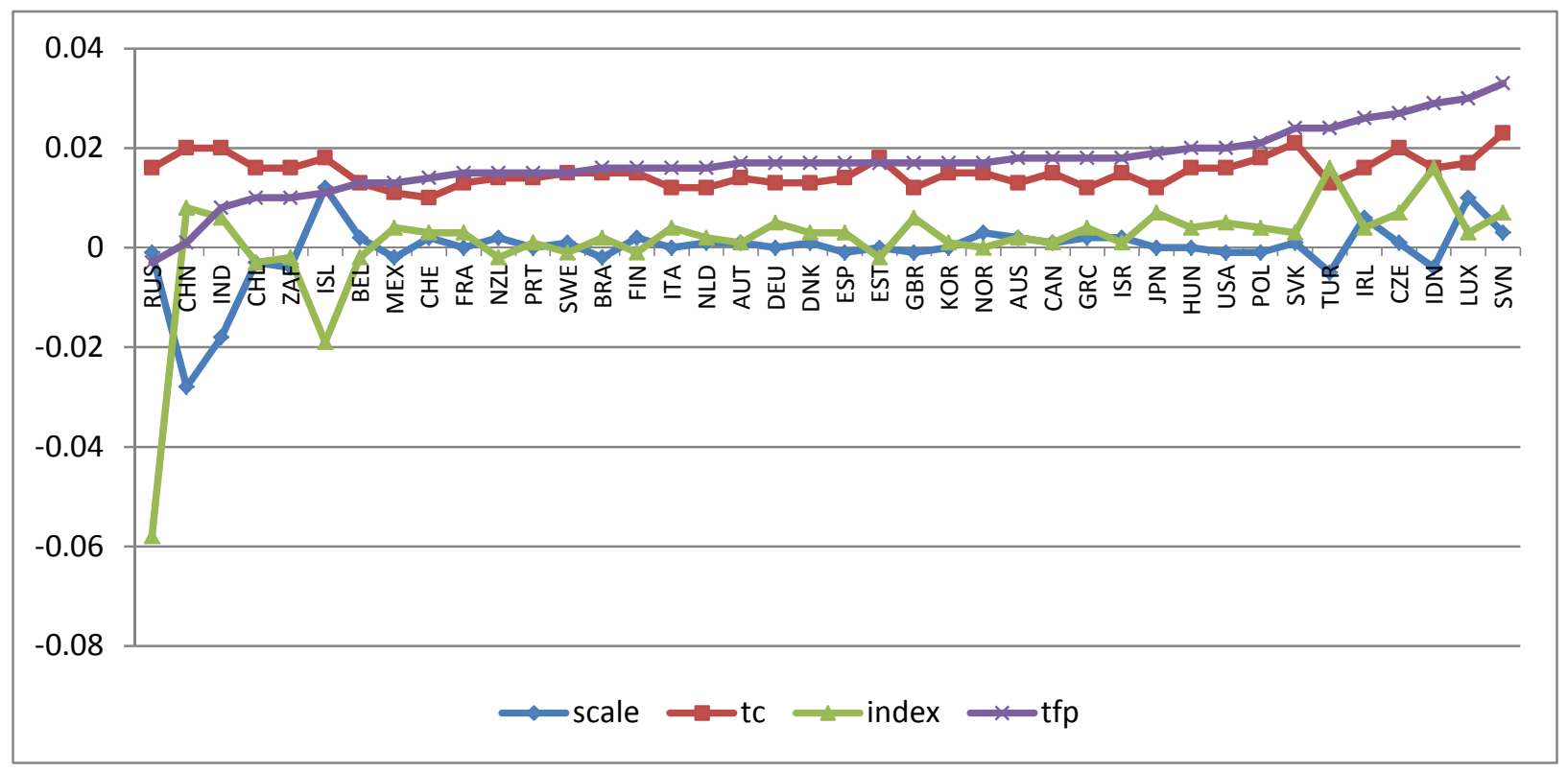

